NBER WORKING PAPER SERIES

\title{
ROADS TO PROSPERITY OR BRIDGES TO NOWHERE? THEORY AND EVIDENCE ON THE IMPACT OF PUBLIC INFRASTRUCTURE INVESTMENT
}

\author{
Sylvain Leduc \\ Daniel Wilson \\ Working Paper 18042 \\ http://www.nber.org/papers/w18042
NATIONAL BUREAU OF ECONOMIC RESEARCH
1050 Massachusetts Avenue
Cambridge, MA 02138

May 2012

\begin{abstract}
We thank Brian Lucking and Elliott Marks for superb and tireless research assistance. We are grateful to John Fernald, Bart Hobijn, Òscar Jordà, John Williams and seminar attendees at the Federal Reserve Bank of San Francisco, the University of Nevada, and the SEEK/CEPR Workshop on "News, Sentiment, and Confidence in Fluctuations," for helpful comments. We thank the many transportation officials who improved our understanding of the institutional complexities of highway financing and spending, especially Ken Simonson (Associated General Contractors of America), Nancy Richardson (formerly of Iowa DOT), Jack Wells (U.S. DOT), and Alison Black and William Buechner (both of American Road and Transportation Builders Assn.) Finally, we are grateful to the editors of the 2012 NBER Macroeconomic Annual for excellent guidance. The views expressed herein are those of the authors and do not necessarily reflect the views of the National Bureau of Economic Research, the Federal Reserve Bank of San Francisco, or the Federal Reserve System.
\end{abstract}

NBER working papers are circulated for discussion and comment purposes. They have not been peerreviewed or been subject to the review by the NBER Board of Directors that accompanies official NBER publications.

(C) 2012 by Sylvain Leduc and Daniel Wilson. All rights reserved. Short sections of text, not to exceed two paragraphs, may be quoted without explicit permission provided that full credit, including $\odot$ notice, is given to the source. 
Roads to Prosperity or Bridges to Nowhere? Theory and Evidence on the Impact of Public Infrastructure Investment

Sylvain Leduc and Daniel Wilson

NBER Working Paper No. 18042

May 2012

JEL No. E62,H54,R11

\begin{abstract}
We examine the dynamic macroeconomic effects of public infrastructure investment both theoretically and empirically, using a novel data set we compiled on various highway spending measures. Relying on the institutional design of federal grant distributions among states, we construct a measure of government highway spending shocks that captures revisions in expectations about future government investment. We find that shocks to federal highway funding has a positive effect on local GDP both on impact and after 6 to 8 years, with the impact effect coming from shocks during (local) recessions. However, we find no permanent effect (as of 10 years after the shock). Similar impulse responses are found in a number of other macroeconomic variables. The transmission channel for these responses appears to be through initial funding leading to building, over several years, of public highway capital which then temporarily boosts private sector productivity and local demand. To help interpret these findings, we develop an open economy New Keynesian model with productive public capital in which regions are part of a monetary and fiscal union. We show that the presence of productive public capital in this model can yield impulse responses with the same qualitative pattern that we find empirically.
\end{abstract}

Sylvain Leduc

Federal Reserve Bank of San Francisco

sylvain.leduc@sf.frb.org

Daniel Wilson

Federal Reserve Bank of San Francisco

101 Market St.

Mail Stop 1130

San Francisco, CA 94105-1530

Daniel.Wilson@sf.frb.org 


\title{
Roads to Prosperity or Bridges to Nowhere? Theory and Evidence on the Impact of Public Infrastructure Investment
}

\author{
by Sylvain Leduc and Daniel Wilson (FRB San Francisco)
}

\section{Introduction}

Public infrastructure investment often plays a prominent role in countercyclical fiscal policy. In the United States during the Great Depression, programs such as the Works Progress Administration and the Tennessee Valley Authority were key elements of the government's economic stimulus. In the Great Recession, government spending on infrastructure projects was a major component of the 2009 stimulus package. Yet, infrastructure's economic impact and how it varies with the business cycle remain subject to significant debate. Many view this form of government spending as little more than 'bridges to nowhere,' that is, spending yielding few economic benefits with large cost overruns and a wasteful use of resources. Others view public infrastructure investment as an effective form of government spending that can boost economic activity not only in the long run, but over shorter horizons as well.

This paper provides both an empirical analysis, using a rich and novel new data set on highway spending, of the dynamic macroeconomic effects of infrastructure investment and a theoretical model to help interpret the results. We focus empirically on highway infrastructure both because it is the largest component of public infrastructure in the United States and because the institutional design underlying the geographic distribution of U.S. federal highway investment helps us identify shocks to local infrastructure spending. In particular, our empirical analysis exploits the formula-based mechanism by which nearly all federal highway funds are apportioned to state governments. Because the state-specific factors entering the apportionment formulas are often largely unrelated to current state economic conditions and also lagged several years, the formula-based distribution of federal highway grants provides an exogenous source of highway funding to states, independent of states’ own economic conditions.

The focus on federal grants to states has the advantage of capturing much more precisely the timing with which highway spending affects economic activity. Public highway spending in the United States is ultimately determined by state governments, which allocate a large fraction 
of their revenues to highway construction, maintenance, and improvement. ${ }^{1}$ However, states report highway spending using the concept of outlays and we show that outlays will often lag considerably the movements in actual government funding obligations that give states the right to contract out and initiate projects. ${ }^{2}$ Furthermore, there can be administrative delays between when a state's grants are initially announced and when the state starts incurring obligations. Using grants to measure the timing of highway spending shocks allows one to estimate possible economic effects stemming from agents' foresight of future government obligations and outlays, even before highway projects are initiated.

In addition, the design and distribution of federal highway spending helps us address concerns related to anticipation effects that are likely to arise in the case of large infrastructure projects. Because the U.S. Congress typically sets the total national amount of highway grants and the formulas by which they are apportioned to states many years in advance, there is strong reason to believe that economic agents (especially state governments and private contractors) can anticipate long in advance, albeit imperfectly, the eventual level of grants received by a given state in a given year. Such anticipation of future government spending has been shown by Ramey (2011a) to pose a serious hazard in correctly identifying spending shocks. ${ }^{3}$

Using the institutional details of the mechanisms by which grants are apportioned to states, and very detailed data on state-level apportionments and national budget authorizations, we construct forecasts of current and future highway grants for each state and year between 1993 and 2010. These forecasts are constructed in much the same way that the Federal Highway Administration constructed forecasts of future highway grants to states at the beginning of the most recent multi-year appropriations act (which covered 2005-2009). From these forecasts, we calculate the expected present discounted value of current and future highway grants. The difference in expectations from last year to this year forms our measure of the shock to state

\footnotetext{
${ }^{1}$ Local governments also spend a considerable amount on road spending, though the vast majority of that spending is on minor residential roads (according to FHWA statistics) that generally are not considered part of the nation's highway infrastructure.

${ }^{2}$ The theoretical implications of these bureaucratic “implementation lags” have been analyzed by Leeper et al. (2009) and others.

${ }^{3}$ Ramey notes that the difficulties may be especially severe with regard to highway spending:

"One should be clear that timing is not an issue only with defense spending. Consider the interstate highway program. In early 1956, Business Week was predicting that the 'fight over highway building will be drawn out.' By May 5, 1956, Business Week thought that the highway construction bill was a sure bet. It fact it passed in June 1956. However, the multi-billion dollar program was intended to stretch out over 13 years. It is difficult to see how a VAR could accurately reflect this program.”
} 
highway spending. This shock is driven primarily by changes in incoming data on formula factors which, as mentioned above, reflect information on those factors from a number of years earlier (because of data collection lags).

We exploit the variation of our shock measure across states and through time to examine its dynamic effect on different measures of economic activity by combining panel variation and panel econometric techniques with time-series techniques. Specifically, we extend Jordà (2005)'s direct projections approach to estimating impulse response functions to allow for state and year fixed effects. We find that these highway spending shocks positively affect GDP at two specific horizons. First, there is a positive and significant contemporaneous impact. This effect is particularly noteworthy given the view by many that infrastructure spending is ill-suited to provide short-run stimulus because of long implementation delays. Second, after this initial impact fades, we find a larger second-round effect around six to eight years out. Yet, there appears to be no permanent effect as GDP is back to its pre-shock level by ten years out.

The multipliers that we calculate from these IRFs are large, roughly 3 on impact and even larger 6-8 years out. These estimates are considerably larger than those typically found in the literature, even those similarly estimating local multipliers with respect to "windfall" transfers from a central government. One possible reason for this is that public infrastructure spending has a higher multiplier than the non-infrastructure spending considered in most previous studies. As we discuss in Section IV, it is also possible that a shock to current and future highway grants leads to increases not just to spending on federal-aid highway projects but also to highway and state spending more broadly. Still, using state in addition to federal highway spending as a broader measure of government outlays, we estimate a lower bound for the peak multiplier of roughly 3.

We obtain the same impulse response pattern when we look at other macroeconomic outcomes, though there is no evidence of an initial impact for employment, unemployment, or wages and salaries. Also, we find some evidence of a permanent positive response of state population to a positive highway funding shock.

Following Auerbach and Gorodnichenko (2011a), we extend the analysis to investigate whether highway spending shocks occurring during recessions lead to different impulse responses than do shocks occurring in expansions. The potential empirical importance of such nonlinearities was emphasized recently in Parker's (2011) survey of the fiscal multiplier 
literature. The results are somewhat imprecise, but we find that the initial impact occurs only for shocks in recessions, while later effects are not statistically different between recessions and expansions.

To explore the channels by which a local shock in federal highway funds leads to increased macroeconomic activity in the short- and medium runs, we also estimate the impulse responses of a number of state fiscal policy variables as well as the responses of particular sectors of the economy most likely to directly benefit from improved highway infrastructure. First, we find that actual grants, obligations, and outlays of federal-aid highway funds do in fact increase over the first several years after a highway funding shock. State highway construction spending also increases but the increase is more gradual with the peak response coming 6-8 years out. Looking at particular sectors of the economy, we find that the shock has is a modest impact effect and a particularly strong second-round effect on GDP in the Truck Transportation sector. Retail sales also show a significant second-round increase though no initial impact.

In the second part of the paper, we use a theoretical framework to interpret our empirical findings. In line with our state-level data set and in the spirit of the recent work by Nakamura and Steinsson (2011), we look at the multiplier in an open economy model with productive public capital in which "states" receive federal funds for infrastructure investment calibrated to capture the structure of a typical highway bill in the United States. By considering an open economy model with nominal rigidities, our approach complements the work of Leeper at al. (2010) in a closed economy context, while by studying changes in productive public capital and government borrowing, our paper complements that of Nakamura and Steinsson (2011). Applying the local projection method to our simulated data, we find a pattern for the movements in the theoretical multiplier that is qualitatively similar to the empirical one: it rises on impact, then falls for some time, before rising once again. We show that this pattern relates to the time it takes to build the public capital stock and to the estimated persistence of shocks to grants. However, our baseline calibration generates a peak multiplier of roughly 2, about eight years after the initial increase in public investment, which is smaller than the second-round effect implied by our empirical impulse response estimates.

This paper is one of the first to analyze the dynamic macroeconomic effects of public infrastructure investment. The sparsity of prior work likely owes to the challenges posed by the endogeneity of public infrastructure spending to economic conditions, the partial fiscal 
decentralization of the spending, the long implementation lags between when spending changes are decided and when government outlays are observed, and the high degree of spending predictability leading to likely anticipation effects. These four features make public infrastructure spending unique and, in particular, different from the type of government spending often analyzed in the literature on fiscal policy, which frequently focused on the effects of military spending (see, Ramey and Shapiro (1998), Edelberg, Eichenbaum, and Fisher (1999), Burnside, Eichenbaum, and Fisher (2004), Fisher and Peters (2010), Ramey (2011a), Barro and Redlick (2011), Nakamura and Steinsson (2011), among others). While defense spending is also subject to implementation lags and anticipation effects, changes in defense spending due to military conflicts are more likely to be exogenous to movements in economic activity than changes in public infrastructure spending.

Because of our focus on highway spending, our paper is more in line with the work of Blanchard and Perotti (2002), Mountford and Uhlig (2009), Fishback and Kachanovskaya (2010), or Wilson (forthcoming) that look at the effects of nondefense spending. ${ }^{4}$ As in the latter two studies, several recent papers have used variations in government spending across subnational regions to identify the effects of fiscal policy. ${ }^{5}$ These studies take advantage of the fact that large portions of federal spending are often allocated to regions for reasons unrelated to regional economic performance or needs, a strategy that we also follow. Such variations can be used to identify the effects of federal spending on a local economy. How these local effects relate to the national effects of federal spending depends on, among other factors, whether there are spillover effects to other regions and the extent to which local residents bear the tax burden of the spending (as stressed in Ramey 2011b). We are able to explore the importance of these factors with our theoretical model.

\footnotetext{
${ }^{4}$ Perotti (2007) and Ilzetzki, Mendoza, and Végh (2010) also apply the methodology of Blanchard and Perotti (2002) to look at the effects of fiscal shocks in countries other than the United States.

${ }^{5}$ In addition to those discussed below, some notable examples using U.S. regional or county level data include Shoag (2010), Chodorow-Reich, et al. (2011), Feyrer and Sacerdote (2010), Conley and Dupor (2011), and Suarez Serrato and Wingender (2011). Likewise, Acconcia, Corsetti, and Simonelli (2011) use variations in public infrastructure spending across Italian provinces. Giavazzi and McMahon (2012) employ a similar approach by looking at the effects of government spending on households' behavior, using disaggregated household information from the Panel Study of Income Dynamics.
} 
We are aware of only a few studies that explicitly investigate the overall economic effects of public highway spending. ${ }^{6}$ Pereira (2000) examine the effects of highway spending, among different types of public infrastructure investment, on output using a structural VAR and aggregate U.S. data from 1956 to 1997. Using a timing restriction à la Blanchard and Perotti (2002), he finds an aggregate multiplier of roughly 2. This approach requires the arguably unrealistic assumption that current government spending decisions are exogenous to current economic conditions. Moreover, Pereira doesn't account for anticipation effects that are very likely to occur in the case of federal highway spending, which may lead to incorrect inference. Using U.S. county data, Chandra and Thompson (2000) attempt to trace out the dynamics of local earnings before and after the event of a new highway completion in the county. They find both that earnings are higher during the highway-construction period (1-5 years prior to completion) than when the highway is completed and that earnings after completion rise steadily over many years. This U-shaped pattern is broadly consistent with our estimated GDP impulse response function with respect to highway spending shocks (which would occur several years prior to a highway completion). A recent paper by Leigh and Neill (2011) estimate a static, cross-section IV regression of local unemployment rates on local federally-funded infrastructure spending in Australia. Because much of that spending in Australia is determined by discretionary earmarks rather than formulas, they use political power of localities as instruments for grants received by localities. Though one might be concerned that local political power also might affect local economic conditions, violating the IV exclusion restriction, they find that local highway grants substantially reduce local unemployment rates.

The remainder of the paper is organized as follows. The next section provides a background discussion about the Federal-Aid Highway Program and details the process through which federal highway grants are distributed among states. We also discuss the issues of timing and forecastability of grants. In Section 3, we first provide evidence on the extent of implementation lags for highway grants and then describe how we construct our measure of highway grant shocks. Our empirical methodology and results are presented in Section 4. In section 5, we present our open economy model and the theoretical multipliers. The last section concludes.

\footnotetext{
${ }^{6}$ Our paper is also related to the long empirical literature on the contribution of public infrastructure capital to the productivity of the private economy (see, for instance, Aschauer (1989), Holtz-Eakin (1994), Fernald (1999), or Morrison and Schwartz (1996)).
} 


\section{Infrastructure Spending: Institutional Design}

The design of the U.S. Federal-Aid Highway Program allows us to specifically address the issues raised in the introduction. In particular, the distribution of federal highway grants across states is subject to strict rules that reduce the concern that these distributions may be endogenous to states' current economic conditions. These rules were also partly implemented to ease long-term planning and thus they provide a natural way to tackle the concern that future spending can be anticipated. Moreover, the data on federal highway funding is detailed enough to distinguish between the provisions of IOUs by the federal government to states and actual government outlays, which mitigates the possible problem arising from implementation lags that obscure the timing of government spending. This section examines each of these features in turn after first providing some background information on highway bills.

Federal funding is provided to the states mostly through a series of grant programs collectively known as the Federal-Aid Highway Program (FAHP). Periodically, Congress enacts multi-year legislation that authorizes spending on these programs. Since 1990, Congress has adopted three such acts: the Intermodal Surface Transportation Efficiency Act (ISTEA) in 1991, which covered fiscal years (FY) 1992 through 1997; the Transportation Equity Act for the 21st Century (TEA-21) in 1998, which covered FY1998-2003; and the Safe, Accountable, Flexible, Efficient Transportation Equity Act: A Legacy for Users (SAFETEA-LU) in 2005, which covered FY2005-2009. ${ }^{7}$ However, legislations of much shorter duration have also been adopted to fill the gap between the more comprehensive, multi-year acts. These so-called stop-gap funding bills typically simply extend funding for existing programs to keep them operational. For instance, since SAFETEA-LU expired in 2009, nine (as of the time of this writing) highway bill extensions of varying durations have been adopted to continue funding highway programs in accordance with SAFETEA-LU’s provisions.

The Federal-Aid Highway Program is extensive and helps fund construction, maintenance, and other outlays on a large array of public roads that go well beyond the interstate highway system. Local roads are often considered Federal-Aid highways and eligible for federal

\footnotetext{
7 The U.S. federal fiscal year begins Oct. 1 of the prior calendar year. For instance, FY2012 runs from Oct. 1, 2011 through Sept. 30, 2012.
} 
construction and improvement funds, depending on their service value and importance. For instance, Figure 1 gives a snapshot of roads categorized as federal-aid highways in downtown San Francisco. While it shows that a major thoroughfare like Highway 101 is included in that category, the figure indicates that many minor roads also fall under the federal-aid highway umbrella.

We note that the cost of construction or improvement of federal-aid highways is not fully covered by the federal government. In most highway programs, the federal government will reimburse a state for 80 percent of the cost of eligible projects, up to the limit set by the state's grant apportionment. Thus, it is important to recognize that not all highway spending on federalaid highway projects is financed by the federal government; some of it is financed by states’ own funds, such as state tax revenues.

\section{A. Distributing Grants to States: Apportionment Formulas}

When a highway authorization bill is passed, Congress authorizes the total amount of funding available for each highway program (highway construction, bridge replacement, maintenance, etc.) for each fiscal year covered by the bill. ${ }^{8}$ For instance, SAFETEA-LU authorized \$244 billion for transportation spending for 2005-2009; 79 percent of that was for the Federal-Aid Highway Program. Nearly all of FAHP funding takes the form of formula grants to state governments: The grants for each individual highway program (Interstate Maintenance, National Highway System, Surface Transportation Program, etc.) are distributed to the states according to statutory apportionment formulas also enacted by Congress as part of the current authorization act. The Interstate Maintenance program, for instance, apportioned funds under SAFETEA-LU according to each state's share of national interstate lane-miles, its share of vehicle-miles traveled on interstate highways, and its share of payments into the Highway Trust Fund, with equal weights on each factor. Table 1 indicates that most programs (and all major programs) use similar formulas. See Appendix A for a more detailed description of the grant distribution mechanism.

\footnotetext{
${ }^{8}$ Transportation authorization acts since the Federal-Aid Highway Act of 1956 have been nominally financed by the Highway Trust Fund (HTF), which receives revenues from fuel, tire, and truck-related excise taxes. However, it is debatable whether the HTF actually plays much of a role in ultimately determining transportation funding levels. That is because there are instances (as in 2008) in which Congress has replenished the HTF from the general fund when the HTF was low, and there are instances in which Congress has taken from from the HTF to add to the general fund (see FHWA 2007). That would suggest the HTF balance at a point in time is largely irrelevant to how much Congress authorizes for subsequent transportation spending.
} 
In the majority of cases, the formulas and their associated factors have changed little over time (i.e., over different authorization acts). However, highway legislation since 1982 also has included a guaranteed minimum return on a state's estimated contributions to the Highway Trust Fund (HTF), which is nominally the financing source for highway authorizations. A state's HTF contributions are the revenues from the HTF's fuel, tire, and truck-related taxes that can be attributed to the state and are estimated by the FHWA based on the same factors used in apportionment formulas. In 1991, the adoption of ISTEA set this minimum guaranteed return to 90 percent, which was then raised to 90.5 percent under TEA-21 in 1998 and 92 percent under SAFETEA-LU. (See Appendix A for more detail.) A benefit of the minimum return requirement, along with the statutory formula apportionment of individual programs, is that it mitigates the potential role of political influence on the distribution of federal funding from year to year. That said, highway bills contain funds earmarked for certain projects that are clearly subject to political influence. For instance, prior to SAFETEA-LU's final legislation, an earlier proposal included an earmark of over \$200 million for the now infamous "Bridge to Nowhere" that was to link Ketchikan, Alaska - with a population of 8,900 - to the Island of Gravina - with a population of 50 . Though this and many other proposed earmarks were ultimately dropped from the final legislation, $\$ 14.8$ billion out of SAFETEA-LU's $\$ 199$ billion of highway authorizations was set aside for earmarks. ${ }^{9}$ However, since earmarks are not distributed according to formulas, we do not use them in our empirical work.

An additional aspect of the apportionment procedure that is key for our empirical strategy is that the factors used in the formulas are lagged three years, since timely information is not readily available to the FHWA. Although the apportionment of federal grants are partly based on factors exogenous to economic activity (lane-miles, for instance), others, like payments into the Highway Trust Fund, may be correlated with movements in current GDP. The use of three-year old data for the factors in the apportionment formulas mitigates the concern that highway spending is reacting contemporaneously to movements in activity.

\section{B. The Forecastability of Grants}

The use of formulas in allocating road funds among states has a long history, going as far back as 1912 with the adoption of the Post Office Appropriation Act, which provided federal aid

\footnotetext{
${ }^{9}$ See Appendix B of FHWA (2007). "Earmarks” are funded by the High-Priority Projects Program.
} 
for the construction of rural postal roads. At the time, the introduction of such formulas was largely welcomed because they made annual grants distribution more predictable and less subject to political influence. They serve the same purpose today, as most highway programs require long-term planning, and advance knowledge of future funding commitments helps smooth operations from year to year. Indeed, before a new highway bill is introduced, the FHWA often estimates what each state is likely to receive each year, using the apportionment formulas. As a result, the Department of Transportation in each state has a good idea of the amount of money the state should expect for each program and can plan accordingly. In the following sections, we use these formulas to generate forecasts, as of each year from 1992 to 2010, of apportionments for each program and for all future years. We show that our forecasts closely match those produced by the FHWA for those years in which FHWA projections are available.

\section{Implementation Lags: Apportionments, Obligations, and Outlays}

Another important aspect of the Federal-Aid Highway Program is that it can entail substantial implementation lags between funding authorization and actually spending. Unlike budget authorizations for most government programs, transportation authorization acts do not directly authorize outlays of federal funds. Rather, the acts give "contract authority" to the FHWA to promise states a certain level of reimbursement (for each highway program and each fiscal year) for eligible highway expenditures. As stated in FHWA (2007),

"It is important to understand that the FAHP is not a 'cash up-front' program. That is, even though the authorized amounts are 'distributed' to the States, no cash is actually disbursed at this point. Instead, States are notified that they have Federal funds available for their use [apportionments]. Projects are approved [obligations] and work is started; then the Federal government makes payments to the States for costs as they are incurred on projects [outlays]." (Bracketed terms added by authors.)

Both because states have up to four years (the period of availability for most programs) to obligate the funds they are apportioned and because outlays occur during and after the completion of highway projects (which by their nature often can take many years), grant apportionments will show up as outlays with varying and possibly lengthy time lags. We use the 
distinction between apportionment announcements, obligations, and outlays to provide evidence on the importance of timing in studying the effects of highway spending on states' economic activity. $^{10}$

To summarize, our empirical strategy will make use of the fact that (1) federal grants are apportioned to states via formulas that use three-year-old factors; (2) by design, the amount of federal grants states receive each year is largely forecastable; (3) highway statistics provide information that likely better capture the timing between highway spending and economic activity.

\section{Measuring Shocks to Highway Spending}

In this section, we detail the construction of our shocks to highway spending, which use revisions in forecasts of federal grants apportionments. Before turning to that topic, however, we first discuss the importance of implementation lags and timing in highway infrastructure projects, which support our use of apportionments to measure our shocks.

\section{A. Implementation Lags and Correctly Measuring the Timing of Highway Spending}

Leeper, et al (2009) and others have convincingly argued that implementation lags between government spending authorization and government outlays can greatly distort inferences regarding the economic impacts of government spending. This is likely to be especially true for highway and other infrastructure spending. The bureaucratic process underlying the implementation lag for highway spending is well detailed in FHWA (2007). The process begins at the beginning of each fiscal year when federal grants are distributed to states according to the formulas laid out in the current highway bill and the factors entering those formulas. Each state then writes contracts with contractors, obligating funds up to a maximum set by current and

\footnotetext{
${ }^{10}$ We are unaware of prior research exploiting data on funding announcements and obligations to better measure the timing of government spending shocks, with the exception of Wilson (2011). Using as instruments formula factors used to distributed funds from the American Recovery and Reinvestment Act (ARRA) of 2009, Wilson estimated the employment effect of ARRA funds alternately based on announcements, obligations, and outlays. He found that the results for announcements and obligations were similar, but that the estimated effect of ARRA funding based on outlays was much larger, likely because a low level of outlays at a given point in time actually represents a much larger level of announcements or obligations which are the true shocks to government spending.
} 
unobligated past grants. ${ }^{11}$ Work then proceeds by contractors and those contractors, along the way and/or at the end of the project, submit bills to their state. The state essentially passes those bills on to the federal government (FHWA) which approves them and instructs the U.S. Treasury to transfer funds to the state which in turn sends funds to the contractor. Note that it is these final transfers of funds by the federal and state governments that show up as "outlays" in official government statistics and ultimately enter the calculation of a state's GDP as part of government spending.

There are at least two steps in this process that can introduce substantial delays between grants and final outlays. First, as noted in the previous section, states legally have up to four years to obligate funds from a given year of grants. Second, and more importantly, once a contract has been written, the work itself may take several years. This, of course, is a distinguishing characteristic of infrastructure spending. Using state panel data that we collected from the FHWA Highway Statistics series (see the data glossary in Appendix C for details), we can estimate precisely what these implementation lags look like. First, we estimate the dynamic lag structure from federal highway grants ("apportionments") received by a state to its obligations of funds for federal-aid highway projects. Specifically, we estimate the following distributed lag model with state and year fixed effects:

$$
O B L I G_{i t}=\alpha_{i}+\alpha_{t}+\sum_{s=0}^{3} \beta_{s} A_{i, t-s}+\epsilon_{i t} .
$$

where $O B L I G$ is obligations and $A$ is apportionments, both per capita.

The results are shown in Table 2. The bottom line is that $70 \%$ of grant money is obligated in the same year the grants are announced and the remaining (roughly speaking) 30\% is obligated the following year. All funds are obligated well within the four-year statutory time frame within which states must obligate federal funds. Thus, the step from grants to obligations introduces only modest implementation lags.

The step from obligations to outlays, however, can lead to substantial lags. This can be seen by estimating a distributed lag panel model as above but with outlays of federal aid as the

\footnotetext{
${ }^{11}$ At this point, the state is also implicitly obligating itself to pay for future auxiliary costs associated with completed highway projects such as highway police services, snow removal, administrative expenses, etc.. Such auxiliary costs show up in data on overall highway outlays but do not show up in data on obligations. For this reason, measured obligations may understate the true level of obligations at a point in time, an issue that affects our interpretation of the government spending multiplier we obtain based on obligations later in the paper. We discuss this in Section IV.D.
} 
dependent variable and obligations on the right-hand side. ${ }^{12}$ Both variables are again per capita. We include current-year and up to seven years of lagged obligations to fully describe the implementation lag process. Further lags are found to be economically and statistically insignificant. The results are shown in the second column of Table 2. We find that a dollar of obligations of federal-aid funds by a state takes up to six years to result in actual outlays (reimbursements to the state) by the federal government. The results in columns (1) and (2) suggest that the implementation lag - often referred to as the "spendout rate" - between grants and outlays is quite long, and this is indeed confirmed when we regress FHWA outlays on current and seven lags of grants. As shown in the third column, $\$ 1$ in grants does eventually lead to $\$ 1$ in outlays (our point estimate is $\$ 0.98$ and the $95 \%$ confidence interval is $\$ 0.88$ to $\$ 1.09$ ), but the process can take up to seven years. In sum, states obligate federal grant funds over two years and those obligations are outlayed over six years, so that the whole process from grants to outlays can take up to seven years. That said, it should also be noted that the process is still highly skewed toward the first two or three years that federal grants are announced, with about $75 \%$ of grant funds showing up as outlays in the first three years.

These results provide strong evidence that there are substantial implementation lags between when highway spending amounts are authorized, and hence known with certainty to all agents in the economy, and when final outlays occur. That is, agents have near-perfect foresight of outlays several years in advance. Thus, one would not want to use outlays in deriving a measure of highway spending shocks in order to estimate the dynamic effects of highway spending. For this reason, we rely instead on information from apportionments (i.e., announced grants) in our analysis. Unanticipated shocks to such announcements may have economic effects both in the short-run, as agents respond now to known future increases in government spending, and in the long-run as they lead to obligations, then actual roadwork, and finally real infrastructure capital being put in place that can potentially enhance productivity in the economy.

\section{B. Distinguishing Unanticipated from Anticipated Changes in Highway Grants}

In this subsection, we construct a measure of highway spending shocks using data from the FHWA on apportionments, statutory formulas, and formula factors from 1993 to 2010. In

\footnotetext{
${ }^{12}$ The data on outlays by the FHWA to states are from the FHWA Highway Statistics for various years. See Table FA-3, "Expenditure of Federal Funds Administered by the Federal Highway Administration During Fiscal Year."
} 
doing so, we make use of the fact that highway spending is likely to be partially forecastable owing to the multi-year nature of the federal highway appropriations acts, which as discussed in Section 2 typically cover a 5-6 year period. In a given year, agents know the full path of aggregate (national) grants for each highway program for the remaining years of the current appropriations bill and they also know the formulas by which each program's grants are apportioned to states. However, they do not know the future values of the factors that go into those formulas and that will determine the distribution of grants among states. At the beginning of each fiscal year, the latest data on formula factors are released at the same time as the year's apportionments are announced. ${ }^{13}$ Importantly for our empirical identification strategy, there is a three-year data-collection lag for these factors. For instance, the number of vehicle-miles traveled on federal-aid highways in each state in 2006 is used, along with other factors in 2006, to apportion Surface Transportation Program grants to states in 2009. As we mentioned in Section 2, this data collection lag helps eliminate potential reverse causality running from current economic activity to formula factors and hence to highway grant apportionments. It also implies that to correctly forecast future apportionments, agents need to make forecasts of the formula factors.

The partial forecastability of future highway apportionments means that observed movements in apportionments may not represent true shocks to expected current and future highway spending. Therefore, we utilize the information provided in each highway appropriations bill to forecast current and future highway spending and then measure the shock to expectations as the difference between the current forecast and last year's forecast. This is similar in spirit to the approach of Ramey (2011a) and especially Auerbach and Gorodnichenko (2011b). The latter paper measures shocks to government spending in OECD countries as the year-over-year change in a one-year ahead forecasts of government spending made by the OECD. One difference between that and what we do here is that our shock is based on a forecast of the present discounted value of all future government (highway) spending rather than just next year's spending.

To construct real-time forecasts of future highway grants, we follow and extend the methodology used by the FHWA Office of Legislation and Strategic Planning (FHWA 2005) in

\footnotetext{
${ }^{13}$ The data on formula factors primarily come from the FHWA's Highway Performance Monitoring System (HPMS).
} 
its report providing forecasts, as of 2005, of apportionments by state for the years of the 20052009 SAFETEA-LU highway bill. Basically, the methodology involves assuming that each state's current formula factors (as a share of the nation), and hence each state's current share of federal grants for each of the 17 FHWA apportionment programs, are constant over the forecast horizon. ${ }^{14}$ That is, the best guess of what the relative values of formula factors will be going forward is their current year relative values. Given apportionment shares for each program, one can then distribute to states the known nationwide totals for each program for the remaining years of the current legislation. One can then aggregate across programs to get a state's total apportionments in each of these future years.

We extend this methodology such that if one is forecasting for years beyond the current legislation, one assumes a continuation of the use of current formulas (i.e., one's best guess of the formulas to be used in future legislations is the formulas currently in use) and one assumes that nationwide apportionments by program grow at the current inflation rate from the last authorized amount in the current legislation. Assuming constant formulas for future bills is reasonable since, as discussed in Section 2, there's been relatively little change in the formulas used to apportion federal grants over the past 20 years. The details of how we construct these forecasts are provided in Appendix B.

As a check on whether our forecast methodology is reasonable and similar to "best practice” for entities interested in forecasting highway apportionments, we compare our forecasts to forecasts we were able to obtain from the FHWA as of 2005. The scatterplot shown in Figure 2 compares our four-year ahead forecasts, as of 2005 (the first year of the 2005-2009 SAFETEULU appropriations bill), of 2009 highway apportionments to that done by the FHWA. The red line is a $45^{\circ}$ line. Not surprisingly given that we use a similar forecasting methodology, our forecasts are very close to the FHWA's.

How forecastable are highway grant apportionments? The answer depends on the forecast year and the forecast horizon, and in particular, on whether one is forecasting grants within the current highway bill or forecasting beyond the current bill. One can see this by comparing fouryear ahead forecasts to actual grants four years ahead for various years of our sample. This is

\footnotetext{
${ }^{14}$ Actually, our assumption is slightly weaker than that. We assume that states who qualify for the minimum apportionment share (usually $0.5 \%$ ) for a given program continue to qualify, which allows for those state's to experience changes in relative formula factors as long as the changes are not big enough to push the state above the minimum apportionment share.
} 
done in Figure 3. The top two scatterplots are for forecast years during the interval of the first highway bill of our sample, ISTEA, which covered 1992-1997. The middle two scatterplots correspond to forecast years during TEA-21, which covered 1998-2003 (but was extended through 2004). The final scatterplots show forecasts, as of 2005, of 2009 grants. Both 2005 and 2009 were within the same highway bill (SAFETEA-LU, covering 2005-2009 but extended at least through the time of this writing). However, 2009 grants also included the large additional amount of grants authorized by the 2009 American Recovery and Reinvestment Act (ARRA). With the exception of the 2005 forecasts, the forecasts made for years within the same bill (left column of scatterplots) tend to miss more or less equally on each side of the $45^{\circ}$ line, whereas the forecasts of grants beyond the current bill tend to miss systematically above or below the line. This reflects the inability to forecast whether the aggregate amount of grants authorized by future bills will be greater or less than current aggregate authorizations. Similarly, the forecast as of 2005 of 2009 grants systematically underpredicted actual 2009 grants due to the inability of a 2005 forecast to predict the large addition of highway grants authorized by the ARRA in 2009.

Using our one-year ahead to five-year ahead forecasts, we calculate the present discounted value (PDV) of current and expected future highway grants for a given state $i$ :

$$
E_{t}\left[P V_{i}\right]=\sum_{s=0}^{5} \frac{E_{t}\left[A_{i, t+s}\right]}{\left(1+r_{t}\right)^{s}}+\frac{E_{t}\left[A_{i, t+5}\right]}{\left(1+r_{t}\right)^{5}} \frac{1}{\left(1-\beta_{t}\right)}
$$

where $E_{t}\left[A_{i, t+s}\right]$ is the forecast as of $t$ of apportionments (in nominal dollars) in year $t+s$ and $\beta_{t}=\left(1+\pi_{t}^{e}\right) /\left(1+r_{t}\right)$. The second term on the right hand side reflects the fact that, because highway appropriations bills cover at most 6 years ( $t$ to $t+5$ ), forecasts beyond $t+5$ simply assume perpetual continuation of $A_{i, t+5}$ (discounted by $\left(1+r_{t}\right)^{5}$ ) growing with expected future inflation of $\pi_{t}^{e}$. We measure the nominal discount rate, $r_{t}$, using a 10-year trailing average of the 10-year Treasury bond rate as of the beginning of the fiscal year $t$ (e.g., Oct. 1, 2008 is the beginning of fiscal year $t=2009$ ). The trailing average is meant to provide an estimate of the long-run expected nominal interest rate. We measure expected future inflation, $\pi_{t}^{e}$, using the median 5- or 10-year ahead inflation forecast for the first quarter of the fiscal year (fourth quarter of prior calendar year) from the Survey of Professional Forecasters (SPF). ${ }^{15}$

\footnotetext{
${ }^{15}$ 5-year ahead forecasts are available in the SPF only from 2006 onward. Prior to 2006, we use the 10-year ahead forecast. The two forecasts are very similar in the data.
} 
The difference between this year's expectation of grants from $t$ onward, $E_{t}\left[P V_{i, t}\right]$, and last year's expectation of grants from $\mathrm{t}$ onward, $E_{t-1}\left[P V_{i, t}\right]$, is then a measure of the unanticipated shock to current and future highway grants. When both $t$ and $t-1$ are covered by the same appropriations bill, as is the case for most of the sample period, this difference primarily will reflect shocks to incoming data on formula factors. When $t$ and $t-1$ span different appropriations bills, this difference also will reflect news in year $t$ about the new path of aggregate apportionments for the next 5-6 years and about any changes to apportionment formulas. Notice that this difference can be decomposed into errors in the forecast of current grants and revisions to forecasts of future grants:

$$
E_{t}\left[P V_{i, t}\right]-E_{t-1}\left[P V_{i, t}\right]=\underbrace{\left(A_{i, t}-E_{t-1}\left[A_{i, t}\right]\right)}_{\begin{array}{c}
\text { Error in Forecast of } \\
\text { Current Spending }
\end{array}}+\underbrace{\left(\sum_{s=1}^{\infty} \frac{E_{t}\left[A_{i, t+s}\right]}{\left(1+R_{t}\right)^{s}}-\sum_{s=1}^{\infty} \frac{E_{t-1}\left[A_{i, t+s}\right]}{\left(1+R_{t-1}\right)^{s}}\right)}_{\text {Revisions to Forecast of Future Spending }}
$$

This decomposition highlights an important difference between our shock measure and the government spending shock measures used in some other studies, such as and Gorodnichenko (2011b) or Clemens and Miran (2010), which are constructed from one-period ahead forecast errors. Forecast errors potentially miss important additional news received by agents at date $t$ about spending more than one period ahead. For certain types of spending with long forecast horizons, such as highway spending, revisions to forecasts of future spending are likely to be important.

We convert these dollar-value shocks into percentage terms (to be comparable across states) using the symmetric percentage formula such that positive and negative shocks of equal dollar amounts are treated symmetrically:

$$
\text { shock }_{t}=\frac{E_{t}\left[P V_{i, t}\right]-E_{t-1}\left[P V_{i, t}\right]}{\left(0.5 \times E_{t}\left[P V_{i, t}\right]+0.5 \times E_{t-1}\left[P V_{i, t}\right]\right)}
$$

To get a sense for what these shocks look like over time and states, in Figure 4 we plot shock $k_{t}$ for a selection of states, over the time period covered by our data. We include several states with large populations (California (CA), Texas (TX), New York (NY), Florida (FL), and Pennsylvania (PA)), a couple of states with large areas but small populations (North Dakota 
(ND) and South Dakota (SD)), and a couple of states with small areas and small populations (Rhode Island (RI) and Delaware (DE)). There is considerable variation over both time and space. As expected, there are large shocks in the first years of appropriations bills - 1998 and 2005. But there also are some large shocks in other years, such as 1996 and 2004. There are no obvious differences in volatility relating to state size or population. For instance, Rhode Island tends to experience large shocks but Delaware does not. Similarly, Pennsylvania displays large shocks while New York does not.

\section{Results - The Dynamic Effects of Highway Spending Shocks on GDP}

\section{A. Estimation Technique}

Our objective in this section is to use our measure of highway spending shocks to estimate the dynamic effects of highway spending on GDP. Our empirical methodology utilizes the Jordà (2005) direct projections approach to estimate impulse response functions (IRFs), extended to a panel context. This approach was also used recently by Auerbach and Gorodnichenko (2011b) in their study of the dynamic effects of government spending, using panel data on OECD countries. The basic specification is:

$$
y_{i, t+h}=\alpha_{i}^{h}+\alpha_{t}^{h}+\sum_{s=1}^{p} \beta_{s}^{h} y_{i, t-s}+\sum_{s=1}^{q} \gamma_{s}^{h} g_{i, t-s}+\delta^{h} \cdot \text { shock } k_{t}+\epsilon_{i, t+h},
$$

where $y_{i, t}$ and $g_{i, t}$ are the logarithms of GDP and government highway spending, respectively, for state $i$ in year $t$, and $s h o c k_{t}$ is the government highway spending shock defined above. The parameter $\delta^{h}$ identifies the impulse response function (IRF) at horizon $h$. Equation (4) is estimated separately for each horizon $h$. Lags of output and highway spending are included to control for any additional forecastability or anticipation of highway apportionment changes missed by our forecasting approach that generates $s_{h o c k}$. We use (log) state federal-aid highway obligations to measure $g_{i, t-s}$ (though using other measures of state highway spending yield similar results). We set $p=q=3$, but find the results to be robust to alternative lag lengths, including $p=q=0$ as we show in the robustness checks below.

The inclusion of state and time fixed effects are important for identification and warrant further discussion. The previous literature estimating the dynamic effects of government spending generally has omitted aggregate time fixed effects. This omission likely is due to the 
difficulty in a dynamic time series model, such as a direct projection or a vector autoregression, of separately identifying a time trend or time fixed effects from the parameters describing the dynamics of the model. The advantage of estimating a dynamic model with panel data is that it allows one to control for aggregate time effects. This is potentially important when estimating the impact of government spending as it allows one to control for other national macroeconomic factors, particularly monetary policy and federal tax policy, that are likely to be correlated over time (but not over states) with government spending.

Notice, however, that by "sweeping out" any potential effect of federal tax policy, we effectively are removing any negative wealth ("Ricardian") effects on output associated with agents expecting increases in government spending to be financed by current and future increases in federal taxes. In other words, to the extent that increases in state government spending are paid for with federal transfers, this spending is "windfall-financed" rather than “deficit-financed"; (see Clemons and Miran (forthcoming)). In reality, state government highway spending, even on "federal-aid" highways, is part windfall-financed - because it is partially reimbursed by federal transfers - and part deficit-financed - both because of the matching requirements for states to receive the transfers and because even reimbursable outlays on federalaid highways necessitates additional non-reimbursable expenditures such as police services, traffic control, snow and debris removal, future maintenance, etc. Our estimated IRFs will reflect any wealth effects from states' deficit financing of matching requirements and non-reimbursable spending, but not wealth effects from the federal government's fiscal policy.

The state fixed effects in equation (4) control for state-specific time trends. Level differences between states in the dependent variable are already removed by the inclusion of a lagged dependent variable on the right-hand side. This can be seen by subtracting the lagged dependent variable from both sides,

$y_{i, t+h}-y_{i, t-1}=\alpha_{i}^{h}+\alpha_{t}^{h}+\left(\beta_{s}^{h}-1\right) y_{i, t-1}+\sum_{s=2}^{p} \beta_{s}^{h} y_{i, t-s}+\sum_{s=1}^{q} \gamma_{s}^{h} g_{i, t-s}+\delta^{h} \cdot s h o c k_{t}+\epsilon_{i, t+h}$.

From this equation, it is clear that $\alpha_{i}^{h}$ represents the average $(h+1)$-year growth in $y_{i}$ for state $i$ over the sample. Controlling for such state-specific time trends is potentially important as states that are growing faster than other states could continually receive higher-than-forecasted grant shares and hence persistently positive shocks. Thus, state-specific shocks could be positively 
correlated with state-specific trends, and omitting such trends could lead to a positive bias on the impulse response coefficients.

One can also see from this equation that, if one were willing to assume a constant linear annual growth rate for each state, a more efficient estimator could be achieved by imposing the constraint that $\alpha_{i}^{h}=\alpha_{i} \cdot(h+1)$. For instance, one could estimate the state-specific time trend, $\alpha_{i}$, from the $h=0$ regression, which uses the maximum number of observations, and then subtract off this estimated parameter from the dependent variable for the other horizon regressions. We found that imposing this constraint led to only a very small narrowing of the confidence interval around the impulse response estimates (and virtually no effect on the IRF itself). Hence, the regressions presented below do not impose this constraint. Because $s_{\text {ock }}$ is constructed to be exogenous and unanticipated, the equation can be estimated via Ordinary Least Squares. However, because the equation contains lags of the dependent variable, the error term is expected to be serially correlated. For this reason, we allow for arbitrary serial correlation by allowing the covariance matrix to be clustered within state.

How does our methodology for estimating IRFs differ from that derived from a VAR? Mechanically, the differences are that (1) the direct projections methodology does not require the simultaneous estimation of the full system (e.g., a 3-variable variable consisting of GDP, highway spending, and the grants shock) to obtain consistent estimates of the IRF of interest (e.g., GDP), and (2) the direct projections methodology estimates the underlying forecasting model separately for each horizon. This methodology offers a number of advantages, particularly in our context, over the recursive-iteration methodology for obtaining impulse responses from an estimated VAR (see Jordà (2005) for discussion). First, direct projections are more robust to misspecification such as too few lags in the model or omitted endogenous variables from the system. The IRF from a VAR is obtained by recursively iterating on the estimated one-period ahead forecasting model. Thus, as Jordà puts it, this IRF "is a function of forecasts at increasingly distant horizons, and therefore misspecification errors are compounded with the forecast horizon.” This is a particular concern in our context given that public infrastructure spending, by its nature, may have real effects many years into the future. By directly estimating the impulse response at each forecast horizon separately, the direct projections approach avoids this compounding problem. 
Second, the confidence intervals from the direct projections IRF are based on standard variance-covariance estimators and hence can easily accommodate clustering, heteroskedasticity, and other deviations from the OLS VC estimator, whereas standard errors for VAR-based IRFs must be computed using delta-method approximations or bootstrapping, which can be problematic in small samples. Third, the direct projections approach can easily be expanded to allow for non-linear impulse responses (for instance, allowing shocks in recessions to have different effects than shocks in expansions, as we explore below). In order to assess the importance of using the direct projections approach instead of a VAR, we also have estimated the GDP impulse response from a 3-variable (GDP, highway spending, and our shock) panel VAR. We discuss the results below.

\section{B. Baseline Results}

We estimate equation (4) using state panel data from 1990 to 2010. The shock variable is only available for years 1993-2010, but the regressions use three lags of spending (obligations) and GDP (or alternative dependent variables). We start by looking at the effects of our shock measure on GDP, before turning to other macroeconomic variables.

The baseline results are shown in Table 3. Panel A of Figure 5 displays the IRF - that is, the estimates of $\delta^{h}-$ for horizons $h=0$ to 10 years. The shaded band in the figure gives the $90 \%$ confidence interval. This IRF indicates that state highway spending shocks lead to a positive and statistically significant increase in state output on impact and one year out. The effect on output falls and becomes negative (though not statistically significantly) over the next few years but then increases sharply around 6-8 years out, before fading back to zero by 9-10 years out.

In Appendix Figure 1, we demonstrate the robustness of this baseline impulse response to a number of potential concerns one might have. Specifically, we find that the results are robust to (1) dropping lags of highway spending; (2) dropping all autoregressive terms; (3) controlling for an index of state leading indicators (from the Federal Reserve Bank of Philadelphia) in case the grant shock is affected by state expected future output; (4) excluding the years 1998 and 2005 in case shocks in the year a highway bill is adopted are endogenous to states' political influence, as states with more political and economic clout could influence the design of apportionment 
formulas to favor their states ${ }^{16}$; (5) considering only the early part of our sample (1993-2004); and (6) considering only the later part of our sample (1999-2010).

Panels B and C show the estimated GDP impulse response functions based on two alternative identification strategies. Panel B shows the results if we measure the $s h o c k_{t}$ variable using only one-year ahead forecast errors of current grants. ${ }^{17}$ As mentioned in the previous section, this shock measure should accurately capture the timing of actual news about government spending but may not fully capture the quantity of that news. In particular, some forecast errors may reflect transitory shocks to government spending while other forecast errors may reflect more persistent shocks which would prompt agents to revise their forecasts of future spending. The current spending forecast errors will not differentiate between these two types of shocks. One can see in Panel B that the IRF obtained from using forecast errors has a similar shape to the baseline IRF (Panel A) except that the peak response is smaller and occurs one year later and the GDP response is still positive by the end of the 11-year window. This suggests that accounting for revisions in forecasts of future spending may not be crucial for estimating shortrun effects but can be quite important for estimating longer-run effects. In addition, the IRF based on forecast errors is estimated much less precisely.

Panel $\mathrm{C}$ shows the results from following the traditional structural VAR type of identification strategy à la Blanchard and Perotti (2002) or Pereira (2000). Specifically, we replace shock $k_{t}$ with current grants in equation (4). Identification here rests on the assumption that the unforecastable component of grants - obtained by controlling for lags of GDP and highway spending (obligations) - can contemporaneously affect GDP but not vice-versa. In other words, this is just the direct projections counterpart to the standard SVAR approach to estimating fiscal policy IRFs. This approach may potentially miss the fact that grants - even conditional on past GDP and spending - may be anticipated to some extent years in advance and hence will not accurately reflect the timing of news. Looking at Panel C, one can see that the resulting IRF has similar longer-run responses to our baseline IRF but shows essentially no short-run impact. It

\footnotetext{
${ }^{16}$ We also tested this idea that political factors could affect our shocks if political influence sways the apportionment mechanisms adoption in new highway bills by regressing on shocks in 1998 and 2005 on the same political factors considered in Knight's (2005) study of the flypaper effect of highway grants. Our shocks are found to be uncorrelated with these political factors.

${ }^{17}$ Specifically, the shock here is the symmetric percentage difference between year $t$ grants and the forecast of those grants as of last year: $\frac{A_{i, t}-E_{t-1}\left[A_{i, t}\right]}{A_{i, t}+E_{t-1}\left[A_{i, t}\right]}$.
} 
may be that this "shock" has no short-run impact because agents previously anticipated it and hence responded in earlier periods.

We also have explored some other alternative identification strategies (results not shown, but available upon request). First, we estimated equation (4) above, but replacing our highway grant shock with current federal-aid obligations and instrumenting for obligations with current and four lags of actual grants. Similar to the SVAR-type identification discussed above, identification here relies on the assumption that a state's grants (relative to the nation's) - being driven by formula factors that are determined three years earlier and only loosely related to GDP - are exogenous with respect to current and future GDP. Again, the drawback of this approach is that it ignores anticipation effects. We find that the IRF from this IV estimation gives very similar results to that based on simply using current grants as in Panel C above.

We also estimated an IRF from a 3-variable (GDP, highway spending, and our shock measure) panel VAR with 3 lags. As in our baseline, identification rests primarily on the a priori measurement of the unanticipated shock to current and future spending (as well as by controlling for lags of GDP and highway spending). However, here the IRF is estimated by recursive iteration on the estimated VAR rather than by the direct projection approach. In other words, the identification restrictions are the same but the estimator differs (as opposed to Panel C which shows the converse). Standard errors are obtained by bootstrapping. We find a significant initial boost in years $t$ and $t+1$, which gradually declines before picking up again around 9-10 years out. However, GDP is still negative by the end of the 10-year horizon. In addition, the $90 \%$ confidence band for this IRF - obtained by bootstrapping - is very large, such that only the initial boost is significant. This pattern is broadly consistent with our baseline results though it underscores the difficulties that VAR-based IRFs have with precisely and robustly estimating impulse responses at longer horizons.

We now turn to estimating the impulse responses of other macroeconomic variables to the highway grants shock. Figure 6 shows the estimate IRFs for GDP per worker, employment (number of workers by state of employment), personal income, wages and salaries, the unemployment rate, and population. ${ }^{18}$ The impulse responses for these first five variables have more or less the same shape as the GDP response. The initial impact, however, is small and

\footnotetext{
${ }^{18}$ Data on the first four of these variables comes from the BEA. We also estimated an IRF based on employment count data from the Bureau of Labor Statistics (BLS) and obtained virtually identical results. Data on unemployment was obtained from the BLS, while data on population comes from the Census Bureau.
} 
insignificant for employment, unemployment, and wages and salaries. All five variables exhibit a positive and significant response around 6-8 years followed by a return to pre-shock levels. Interestingly, population is the only variable that appears to be permanently affected by the highway shock. A natural interpretation of this result is that highway/road improvements enable population growth as, for example, new housing developments are built around new or improved roads and as new commuting options are made possible. Such a response is consistent with Duranton and Turner's (2011) recent finding that increases in a state's road lane-miles cause proportionate increases in vehicle miles traveled.

\section{Transmission Mechanism}

What explains these macroeconomic responses? In this subsection, we first look at the responses of variables that could be directly affected by a highway grant shock, as opposed to indirectly affected through general equilibrium channels, in order to begin to formulate a general explanation of the macroeconomic effects of highway grants. We thus look at the response of actual grants, obligations, and outlays on federal-aid highways. These are the three variables whose relationships were analyzed in Section III. The results are shown in Figure 7. Not surprisingly, an unanticipated shock to expectations of current and future grants is in fact followed by actual increases in grants immediately and up to four years out. This is also consistent with the fact that grants become increasingly difficult to forecast as the forecast horizon goes beyond six or more years, which is the typical length of a highway bill. Obligations also increase for the first 3-4 years after the shock and also appear to rise again eight years out. Outlays actually fall on impact but then are higher for years $t+1$ to $t+5$ and again at $\mathrm{t}+8$.

These patterns are consistent with the notion that a shock to expected future grants leads to initiation of actual highway projects - and hence obligations - over the next 3-4 years, which with some lag leads to project completions and hence outlays. This interpretation is supported by the response of state government total highway construction spending (total, not just on federalaid roads), which is also shown in Figure 7. State highway construction spending increases from

years $t+1$ to $t+4$ (though it is only statistically significant for $t+1$ ) and then rises again around $t+6$ to $t+9$. This latter increase in state highway spending could reflect improved state finances due to higher overall economic activity. Indeed, as shown in the bottom two panels of Figure 7, state 
government tax revenues and overall state government spending are found to be higher around 78 years after an initial highway grant shock.

Combining these results with the macroeconomic responses in Figure 6, particularly the increase in GDP per worker 6-8 years after the shock, the results point to a possible productivity effect of improved highway infrastructure. Under this interpretation of our results, an initial shock to federal grants leads to highway construction activity over the following 3 to 5 years and results in new (or improved) highway capital put in place around 6-8 years out. In turn, the new highway capital triggers higher productivity in transportation-intensive sectors, reducing goods prices and boosting demand. Ultimately, the increase in economic activity raises state tax revenues and increases state government spending as a result.

To dig deeper into this interpretation of our results, we examine whether transportationintensive sectors do in fact experience a boost in activity around the time new highway capital would be coming on-line by estimating the response of GDP in the Truck Transportation sector to our shock measure. The results are shown in Figure 8. Consistent with the response of overall GDP, we find a small initial response, which is followed by a very large second-round effect 5-6 years out, in line with the view that completed highway projects would directly benefit the local truck transportation sector. Similarly, the response of retail sales shown in Figure $\mathbf{8}$ also rises when highway project are likely completed, 6 to 7 years after a shock to federal grants. ${ }^{19}$ The increase in retail sales likely also reflects higher overall consumption occurring in tandem with the increase in GDP, personal income, wages and salaries, and other macroeconomic variables.

\section{The GDP Multiplier}

How large are our baseline GDP effects? The impulse response estimates, $\delta^{h}$, represent the percentage change in GDP with respect to a one-unit change in shock $k_{t}$ The common practice in the literature for converting such percentage responses into dollar multipliers is to first normalize the GDP responses such that a one unit change in the shock represents a 1\% change in government spending. One can then multiply the resulting elasticity by the average ratio of GDP to highway spending in the sample to obtain a multiplier. However, it is not always clear in such

\footnotetext{
${ }^{19}$ We thank Chris Carroll and Xia Zhou for providing their state-by-year data on retail sales (see Zhou and Carroll 2012). [Zhou, Xia, and Christopher D. Carroll. "Dynamics of Wealth and Consumption: New and Improved Measures for U.S. States," B.E. Journal of Macroeconomics, 12(2), March 2012. Unfortunately, state level data on overall consumption (beyond extrapolations from retail sales) is not available.
} 
an exercise, especially in a context like ours where there are multiple concepts of highway spending that one might consider, which measure of spending to use. Here, we report multipliers based on a range of alternatives. For each alternative, we report the multiplier on impact, the peak multiplier, and the mean multiplier. If one measures highway spending using only FHWA grants (or obligations), the multiplier on impact is about 3.4, the peak multiplier (at 6 years out) is 7.8, and the mean multiplier is $1.7 .^{20}$ These multipliers may well be unrealistically large in that a shock to current and future grants may fail to reflect broader changes to government highway spending. For instance, highway grants for federal-aid highways may lead to subsequent expenditures by state and local governments on local roads, traffic control, highway police services, etc. The extent to which federal transfers to local governments earmarked for a specific purpose actually increase spending by regional governments on that purpose is known as the flypaper effect. $^{21}$

If one uses a broader measure of highway spending, such as state government outlays on highway construction, the implied multipliers are smaller but still large. The impact multiplier would be 2.7, the peak multiplier 5.9, and the mean multiplier $1.3 .^{22}$ One might also consider using an even broader measure like state government spending for all road-related activities. Unfortunately, such data is not available. ${ }^{23}$ However, while such spending represents a larger fraction of GDP than the other measures, we obtain a much smaller (and imprecisely estimated) response of total road spending to the grants shock. Nonetheless, if one allows for the possibility that a shock-induced rise in grants lead to a proportional rise in total state government road spending, our estimated responses multiplied by the average ratio of GDP to road spending provide a lower bound on the impact multiplier of 1.4 and the peak multiplier of 3.0. The bottom line is that based on the most sensible measures of government highway infrastructure

\footnotetext{
${ }^{20}$ The impact and peak impulse response coefficients are 0.0115 and 0.0259 , as seen in Table 3 . The mean response from the impulse response coefficients in Table 3 is 0.0055 . The cumulative percent response of grants to a one unit change in our shock is roughly 1 and the average ratio of state GDP to grants is about 300 . So the implied impact multiplier is the estimated GDP IRF coefficient, 0.0115, times 300, which equals 3.4.

${ }^{21}$ The recent literature on the flypaper effect of federal grants has found mixed results. Studies by Baicker (2001); Evans \& Owens (2005), Singhal (2008), and Feiveson (2011) find evidence of strong flypaper effects across a variety of spending categories. However, Knight (2002) and Gordon (2004) find the opposite.

22 The cumulative percent response of this variable to our shock also is close to one, and the average ratio of GDP to highway construction spending is 238 .

${ }^{23}$ In particular, data on obligations by state governments for all highway-related activities does not exist. Data on outlays by state governments for such activities does exist, but as we pointed out in Section II, outlays represent a poor measure of actual roadwork and related activities.
} 
investment, the GDP multiplier implied by our estimated impulse responses appear to be considerably larger than those based on defense or overall government spending as estimated in previous studies.

\section{E. Extensions}

1. Impact of Highway Spending Shocks in Expansions vs. Recessions

In this subsection, we report the results of a number of interesting extensions of the baseline results. First, we explore whether the effects of government highway spending are different depending on whether the shock occurs in an expansion or a recession. We follow the approach of Auerbach and Gorodnichenko (2011b), which involves calculating the probability of being in an expansion (vs. recession), based on a regime-switching model, and interacting that probability with the right-hand side variables in the direct projection regressions (equation (4)). Expansions and recessions here are local (state-specific). As in Auerbach and Gorodnichenko, we first calculate for each state and year the deviation of real GDP growth from the state's longrun trend (estimated from a HP filter with a high smoothing parameter of 10,000). We then take a logistic transformation of that variable in order to map it onto the $[0,1]$ range. The IRF of output with respect to highway spending shocks during an expansion is given by the coefficient, for each horizon $h$, on the interaction between the shock and the expansion probability. ${ }^{24}$ Conversely, the IRF during a recession is given by the coefficient, for each horizon, on the interaction between the shock and one minus the expansion probability. Note that because the regression controls for aggregate time fixed effects, the identifying variation for our IRFs is states' expansion probabilities relative to the national business cycle. Also note that the use of the direct projections approach, as opposed to a non-linear VAR as in Auerbach and Gorodnichenko (2011a), does not require an assumption that the local economy remains in the same regime throughout the interval $t$ to $t+h .^{25}$ The direct projections approach simply estimates the conditional mean of GDP $h$ years after a shock that occurs in a recession (or

\footnotetext{
${ }^{24}$ To avoid potential simultaneity bias from the fact that the expansion probability will be contemporaneously correlated with the dependent variable (log output), we follow Auerbach and Gorodnichenko (2011b) in lagging the expansion probability by one year.

${ }^{25}$ See Ramey (2011b) for a critique of that assumption.
} 
expansion). The fact that GDP typically exits recession within a year or two will not affect this conditional mean because we control for the recession probability term separately from the interaction of that probability with the shock. Moreover, if the shock itself helps push a local economy out of recession, this will be reflected in the impulse response function.

The results are shown in Figure 9. The top panel shows the results for recessions; the bottom panel shows results for expansions. Interestingly, the initial impact of highway spending shocks are much larger when they occur in state-years experiencing a recession. The impact elasticity in recessions is 0.028 (s.e. $=0.015$ ), which is statistically significant at the $10 \%$ level and about twice as large as the average impact response (as found in our baseline regressions in Table 3). The impact elasticity in expansions, on the other hand, is slightly below zero and statistically insignificant. After the initial shock, the output response from shocks hitting during recessions falls and becomes statistically insignificant. For shocks hitting during expansions, the output response grows slightly over time but remains statistically insignificant. There is a significant increase in GDP at $t+10$ for recessions and a significant decrease at $t+10$ for expansions. Overall, these results suggest that the initial positive impact of highway spending shocks found in the baseline results is driven by the large effect on such spending in recessions, while the second-round positive effects coming six to eight years later may be independent of the business cycle conditions at the time of the shock.

\section{The 2009 American Recovery and Reinvestment Act and the Great Recession}

The 2008-2009 severe recession (and subsequent weak recovery) and the large one-time increase in federal highway grants from the 2009 American Recovery and Reinvestment Act (ARRA) suggest that the response of local economic activity to government highway spending may have been different over this time period than the "usual” response. First, we ask whether the effect of highway grants on local GDP was unusually large during the Great Recession. We investigate this by extending our baseline direct projections regressions (equation (4)) by interacting the shock with year dummies. As we only have data through 2010, we focus here on the contemporaneous and one-year ahead responses. The estimated impulse response coefficients by year are shown in Panel A of Table 4. We find that both the contemporaneous and the yearahead effects on GDP were significantly higher from highway shocks in 2009 than the average effect over the 1993-2010 sample (0.012 from Table 3). We also find other years that have 
significantly different effects than the average: highway shocks in 2000 also had large positive effects, while shocks in 2001 and 2006 had negative effects. Notice that these effects cannot simply be explained by national cyclical conditions because national conditions are "swept out" by the aggregate time fixed effects. Rather, these results indicate that local GDP relative to national GDP was impacted more by highway grant shocks in 2000, 2001, 2006, and 2009 than in other years. This could be due, for instance, to differences in the nature or composition of highway grants in different years.

Of course, 2009 was an atypical year not just because of the severe recession, but also because of the extraordinary fiscal and monetary policy actions taking place. In particular, the American Recovery and Reinvestment Act enacted in February 2009 authorized a very large one-time increase of $\$ 27.5$ billion in highway grants. Because the Act was designed to provide short-term economic stimulus, the Act stipulated that these grants had to be entirely obligated by March 2010. Therefore, the ARRA grants typically were used by state governments for projects involving shorter planning and construction horizons than were non-ARRA grants. It is quite possible that such shorter-horizon projects have different effects on GDP than longer-horizon projects.

To assess this further, we separated out the ARRA grants from the non-ARRA grants in our construction of the expected present value of current and future grants (see equation (2)) to obtain an ARRA grants shock and a non-ARRA grants shock. The bulk of ARRA grants were apportioned in fiscal year 2009, but some were also apportioned in fiscal year 2010 (October 2009 through September 2010). We then extended the regression underlying Panel A by replacing the overall shock (interacted with year dummies) with these two separate shocks (interacted with year dummies). Of course, in years prior to 2009, the non-ARRA shock is just the overall shock and the ARRA shock is zero. The results are shown in Panel B of Table 4. We find that a state with 10\% higher 2009 ARRA grants than the national average saw $0.33 \%$ higher GDP in 2009 and $0.32 \%$ higher GDP in 2010. A state with 10\% higher non-ARRA grants in 2009 saw 0.67\% higher GDP in 2009 and 0.83\% higher GDP in 2010. Both types of grants appear to have had no contemporaneous impact in 2010. Given that the ratio of non-ARRA grants to ARRA grants in 2009 was about 2.8, the estimated multiplier on a dollar of ARRA grants is just slightly higher than that of non-ARRA grants. Thus, we find that the ARRA grants did have a significant positive effect on states' economies and that the effect of a dollar of 
ARRA grants was not materially different from the effect of a dollar of ordinary federal highway grants.

\section{Theory - Multipliers in a Model with Productive Public Capital}

In this section we turn to assessing the impact of public infrastructure investment in a theoretical framework with productive public capital. Our model is relatively standard and contains many features that have proven useful in addressing the macroeconomic impact of fiscal policy (see, Baxter and King (1993), or the more recent analysis of Leeper et al (2010) and Uhlig (2011), using closed economy models, and Corsetti, Kuester, and Müller (2011), in the context of a small open economy). In line with our empirical framework above and in the spirit of Nakamura and Steinsson (2011), we conduct our analysis in a monetary union using an open economy model, which allows us to remove the effects of aggregate shocks and monetary policy on the local fiscal multiplier.

We consider a cashless national economy consisting of two regions, $H$ and $F$, of possibly different sizes, $n$ and $1-n$. The national government invests in public infrastructure projects in the two regions and finances these investments by levying taxes and by borrowing. Each region specializes in one type of tradable good, produced in a number of varieties or brands, defined over a continuum of unit mass. Firms are monopolistic suppliers that combine private and public capital with domestic labor to produce one brand of goods. Throughout the section, we assume complete financial markets.

We first provide a description of the households and the behavior of the monetary and fiscal authorities, before presenting the firms' problem.

\section{A. Households}

The Home region is populated by a continuum of infinitely-lived households who choose a consumption basket, $C_{t}$, and hours worked, $L_{t}$, to maximize the expected value of their lifetime utility given by

$$
E_{0} \sum_{t=0}^{\infty} \beta^{t} U\left(C_{t}, L_{t}\right)
$$


where $\beta$ denotes the agent's subjective discount factor. ${ }^{26}$ Home households consume all the different types of traded goods produced in the two regions, with $C_{t}(h)$ representing the consumption of the Home region's brand $h$ at time $t$, while $C_{t}(f)$ is the consumption of the Foreign region's brand $f$. For each type of good, we assume that one brand is an imperfect substitute for all other brands, with constant elasticity of substitution $\theta$. Consumption of Home and Foreign goods by the Home agent is defined as:

$$
C_{\mathrm{H}, t} \equiv\left[\int_{0}^{1} C_{t}(h)^{\frac{\theta-1}{\theta}} d h\right]^{\frac{\theta}{\theta-1}}, \quad C_{\mathrm{F}, t} \equiv\left[\int_{0}^{1} C_{t}(f)^{\frac{\theta-1}{\theta}} d f\right]^{\frac{\theta}{\theta-1}}
$$

In turn, Home households' full consumption basket is composed of the bundles of Home and Foreign produced goods defined by the following CES aggregator

$$
C_{t} \equiv\left[a_{\mathrm{H}}^{\frac{1}{\eta}} C_{\mathrm{H}, t}^{\frac{\eta-1}{\eta}}+\left(1-a_{\mathrm{H}}\right)^{\frac{1}{\eta}} C_{\mathrm{F}, t^{\frac{\eta-1}{\eta}}}\right]^{\frac{\eta}{\eta-1}}, \quad \eta>0,
$$

where $a_{\mathrm{H}}$ dictates the degree of home bias in consumption ( $a_{\mathrm{H}}=0.5$ equates to no home bias) and where the elasticity of substitution between the consumption of Home goods and the consumption of imports is given by $\eta$. The price index associated with the consumption aggregator is given by

$$
P_{t} \equiv\left[a_{\mathrm{H}} P_{\mathrm{H}, t}^{1-\eta}+\left(1-a_{\mathrm{H}}\right) P_{\mathrm{F}, t}(j)^{1-\eta}\right]^{\frac{1}{1-\eta}},
$$

where $P_{\mathrm{H}, t}$ is the price sub-index for home-produced goods and $P_{\mathrm{F}, t}$ is the price sub-index for foreign produced goods, both expressed in the common national currency:

$$
P_{\mathrm{H}, t} \equiv\left[\int_{0}^{n} P_{t}(h)^{1-\theta} d h\right]^{\frac{1}{1-\theta}}, \quad P_{\mathrm{F}, t} \equiv\left[\int_{0}^{n} P_{t}(f)^{1-\theta} d f\right]^{\frac{1}{1-\theta}} .
$$

The Home households derive income from working, $W_{t} L_{t}$, from renting capital to firms, $R_{t} K_{t}$, and from the state-contingent payoffs $B_{t}(s)$ in state of nature $s$. We assume that the profits of Home firms are rebated to Home households in the form of dividends, $\Pi(h)$.

In line with the spirit of highway infrastructure financing in the United State, our baseline model assumes that public infrastructure spending is financed with a consumption tax, $\tau^{c},{ }^{27}$ That said, since 2005 every state received as much or more funding for highway programs than they contributed in highway taxes (see GAO (2010)). This reflects the fact that more funding has been

\footnotetext{
${ }^{26}$ For convenience, we do not index variables by households.

${ }^{27}$ In practice, the revenues of the Highway Trust Fund are derived from excise taxes collected on motor fuel and truck-related taxes. For simplicity, we proxy those taxes with a general consumption tax.
} 
authorized and apportioned to the states than funds in the Highway Trust Fund allowed, with the discrepancy paid for with general revenues. For simplicity, our baseline model abstracts from this possibility. Note, however, that our approach to calculating our theoretical multipliers follows our empirical one above and thus removes the effects of federal fiscal policy through the introduction of time fixed effects.

Households use their disposable income to consume, invest in domestic capital, and buy state-contingent assets $B_{t+1}(s)$, which pays one unit of Home consumption goods if a particular state of nature $s$ occurs in period $t+1$, at price $p_{b t, t+1}$. The households can also invest in a one-period government bond, $B_{t+1}^{G}$, which has a price $p_{b t}^{g}$.

We assume that, as with aggregate consumption, aggregate private investment is a CES composite of Home and Foreign tradable goods with identical weight and elasticity. Private capital accumulates according to the following law of motion

$$
K_{t+1}=(1-\delta) K_{t}+I_{t},
$$

where $\delta$ denotes the depreciation rate. The individual flow budget constraint for the representative agent in the Home country is therefore:

$$
\begin{aligned}
\left(1+\tau_{t}^{c}\right)\left(P_{\mathrm{H}, t} C_{\mathrm{H}, t}+P_{\mathrm{F}, t} C_{\mathrm{F}, t}\right)+P_{t} I_{t}+\int_{s} & p_{b t, t+1} B_{t+1}(s) \\
& \leq W_{t} L_{t}+R_{t} K_{t}+B_{t}(s)+\int_{0}^{1} \Pi_{t}(h) d h-T_{t} .
\end{aligned}
$$

\section{B. Fiscal and Monetary Policies}

As discussed in Sections II and IV.A, there can be long implementation lags between the time when government transportation spending is authorized and when actual outlays occur. Following Leeper et al (2010), we capture this feature of government investment by assuming that only a fraction of authorized funds show up as spending in a given year.

Let $A_{\mathrm{H}, t}$ denote the federal grants per capita apportioned to region $\mathrm{H}$ at time $t$, which we assume follows an $\operatorname{AR}(1)$ process

$$
A_{\mathrm{H}, t}=\left(1-\rho_{A}\right) \bar{A}_{\mathrm{H}}+\rho_{A} A_{\mathrm{H}, t-1}+\varepsilon_{A},
$$

where $\bar{A}_{\mathrm{H}}$ is the steady state level of region H's apportionments and $\varepsilon_{A}$ denotes an unanticipated shock. In turn, we denote per capita government infrastructure outlays (by all levels of 
government, net of intergovernmental transfers) in the Home region by $G_{\mathrm{H}, t}^{I}$ and assume that it evolves according to the following process

$$
G_{\mathrm{H}, t}^{I}=\sum_{n=0}^{N-1} \omega_{n} A_{\mathrm{H}, t-n}
$$

where $\sum_{n=0}^{N-1} \omega_{n}=1$. The spend out rates, i.e., the rate at which authorized funds will show up as government outlays, is determined by $\omega_{i}, i=0, \ldots, N-1$.

Because it may take time for public infrastructure projects to be completed, we introduce a time-to-build component by letting government funds apportioned at time $t$ only impact the public capital stock $J$ periods later:

$$
K_{\mathrm{H}, t+1}^{G}=(1-\delta) K_{\mathrm{H}, t}^{G}+A_{\mathrm{H}, t-J} .
$$

We assume that public capital in a region is a composite good, given as a CES index of the differentiated goods in that region, and for simplicity we assume that the public investment index has the same form as the consumption index in (6).

$$
A_{\mathrm{H}, t}=\left[\int_{0}^{1} A_{t}(h)^{\frac{\theta-1}{\theta}} d h\right]^{\frac{\theta}{\theta-1}},
$$

so that the government's demand for each type of differentiated good is given by

$$
A_{t}(h)=\left(\frac{P_{t}(h)}{P_{\mathrm{H}, t}}\right)^{-\theta} A_{\mathrm{H}, t}, \quad A_{t}(f)=\left(\frac{P_{t}(f)}{P_{\mathrm{F}, t}}\right)^{-\theta} A_{\mathrm{F}, t}
$$

Using consumption taxes to finance government purchases, the national government's budget constraint is

$$
\tau_{t}^{c}\left(n P_{t} C_{t}+(1-n) P_{t}^{*} C_{t}^{*}\right)=n P_{\mathrm{H}, t} G_{\mathrm{H}, t}^{I}+(1-n) P_{\mathrm{F}, t}^{*} G_{\mathrm{F}, t}^{I},
$$

where asterisks denote foreign variables.

Similar to Nakamura and Steinsson (2011), monetary policy is set at the national level according to an interest-rate rule that is a function of aggregate consumer price inflation, $\widehat{\pi}_{t}^{a g}$, and aggregate output, $\widehat{y}_{t}^{a g}$, given by

$$
\widehat{r}_{t}=\rho_{R} \widehat{r}_{t-1}+\beta_{\pi}\left(1-\rho_{R}\right) \widehat{\pi}_{t}^{a g}+\beta_{y}\left(1-\rho_{R}\right) \widehat{y}_{t}^{a g},
$$

where hatted variables denote deviations from steady state and where aggregate inflation and aggregate output are weighted sums of respective variables in the Home and Foreign regions: $\widehat{\pi}_{t}^{a g}=n \widehat{\pi}_{t}+(1-n) \widehat{\pi}_{t}^{*}$ and $\widehat{y}_{t}^{a g}=n \widehat{y}_{t}+(1-n) \widehat{y}_{t}^{*}$. 


\section{Firms' Problem}

Firms producing Home tradables are monopolist in producing their brand; they employ a technology that combines domestic labor with private and public capital inputs, according to the following Cobb-Douglas function:

$$
Y_{t}(h)=L_{t}(h)^{\phi} K_{t}(h)^{1-\phi} K_{t}^{G}(h)^{\phi_{g}}
$$

where $K_{t-1}^{G}(h)$ is public capital used in the production of good $h$. Positive value of $\phi_{g}$, the elasticity of output with respect to public capital, imply that the production function has increasing returns with respect to public capital, as in the analysis of Baxter and King (1993) and Leeper et al (2010). ${ }^{28}$

We assume that there is no impediment to goods trade across regions, so that the law of one price holds. Moreover, in setting their prices, firms take into account the fact that, in any given period, there is a probability $\alpha$ that they will have to leave prices unchanged as in Calvo (1983). When they can reset their prices (which occurs with probability $1-\alpha$ ), firms act to maximize the expected discounted sum of profits

$$
\Pi_{t}(h)=E_{t}\left\{\sum_{k=0}^{\infty} p_{b t, t+k} \alpha^{k}\left(P_{t}(h) Y_{t+k}(h)-M C_{t+k}(h) Y_{t+k}(h)\right\},\right.
$$

where $M C_{t}$ is the firm's nominal marginal cost and where the firm's demand at time $t$ is given by

$$
Y_{t}(h)=\left(\frac{P_{t}(h)}{P_{\mathrm{H}, t}}\right)^{-\theta}\left(n C_{\mathrm{H}, t}+(1-n) C_{\mathrm{H}, t}^{*}+n I_{\mathrm{H}, t}+(1-n) I_{\mathrm{H}, t}^{*}+n A_{\mathrm{H}, t}\right) .
$$

\section{Calibration}

In our baseline calibration, we parameterize the size of the Home country, $n$, to $\frac{1}{50}$ to correspond to a U.S. state in our empirical data set. We use the following preferences

$$
U\left(C_{t}, L_{t}\right)=\frac{C_{t}^{1-\sigma}}{1-\sigma}-\psi \frac{L_{t}^{1+\xi}}{1+\xi},
$$

and set the coefficient of relative risk aversion, $\sigma$, to 1 and the value of $\xi$ to imply a Frisch labor elasticity of 0.75 . As an alternative, we also consider the preferences in Greenwood, Hercowitz,

\footnotetext{
${ }^{28}$ Studying optimal taxation in a model with productive capital, Lansing (1998) assumes a production function with constant return to scale. Moreover, we abstracts from issues related to congestion of public goods. On this question, see the work of Glomm and Ravikumar (1994).
} 
and Huffman (1998), which have been used to study the effects of fiscal policy (see, among others, Monacelli and Perotti (2008) and Nakamura and Steinsson (2011)). We calibrate the model to an annual frequency and set the discount factor, $\beta$, to 0.96 . To determine the value of the elasticity of substitution across goods' varieties we use a markup of 20 percent in steady state, implying that $\theta=6$.

The extent to which regions are relatively open to trade can have an important effect on the size of the fiscal multiplier through a "leakage" effect associated with movements in goods between regions. Our baseline calibration follows Nakamura and Steinsson (2011), as we set $a_{\mathrm{H}}$ to 0.69 in light of their evidence on goods shipments across U.S. states. Moreover, we assume that households view goods from different U.S. regions as being fairly substitutable, and set the elasticity of substitution to 4 . Since there is a lot of uncertainty surrounding this parameter value empirically, we look at the robustness of our results to variation around this baseline calibration.

For the goods production function, we use a labor share of 70 percent. However, the range of empirical estimates of the output elasticity of public capital, $\phi_{g}$, is very wide. In a review of the early estimates of this elasticity for the United States, Munnell (1992) reports the findings of 9 studies, with estimates ranging between 0.05 and 0.4 . While we set $\phi_{g}=0.1$ in our baseline model to facilitate comparison with other studies (e.g., Baxter and King (1993) and Leeper et al (2010)), we also experiment with different values given this uncertainty. In particular, we will examine the change in the fiscal multiplier when public capital is unproductive, i.e., $\phi_{g}=0$.

We calibrate the steady state share of government purchases in output to 0.3 percent in line with the 1993-2010 average value across states in our dataset. We think of infrastructure spending as being authorized for 5 years, the same duration as the SAFETEA-LU bill covering 2005 through 2009 (inclusive), but less than the previous two bills that both lasted 6 years. Because implementation lags make the concept of obligations more meaningful for economic activity that that of outlays, we use the implementation lags between grants and obligations estimated in Table 2 to calibrate the spend out rate $\omega$ in equation (13). Thus, 70 percent of grants apportionments are obligated in the current year and 30 percent the following one.

The construction of new highways takes a very long time. The General Accounting Office reports that typical new highway construction projects take between 9 to 19 years from planning to completion (see GAO (2002)). However, new highway construction projects 
constitute only about 3 percent of federally funded projects. Although most of the spending in highway bills is directed toward road improvement and maintenance instead of the construction of new roads, the General Accounting Office nonetheless reports that most such projects necessitate between 4 to 6 years before being completed. Based on this assessment, we assume that the time-to-build process in equation (14) takes 4 years $(J=4)$.

The probability that firms update their prices is chosen such that prices are on average fixed for 4 quarters. The coefficients in the interest-rate rule are set to the following values$\rho_{R}=0.8, \beta_{\pi}=1.5$, and $\beta_{y}=0.5$ - though monetary policy will not affect our estimates of the local multiplier as it will be differenced out.

Finally, we set the persistence of the shocks to apportionments to 0.27 , a value consistent with regressing states' highway grants on one lag, as well as state and time fixed effects for the period covered by our dataset. Thus a shock essentially dies out after 4 years, which is also consistent with the response of highway grants to our shock measure in Figure 8. Throughout our exercises, we look at the effect of one percent shocks to government spending.

\section{E. Findings}

In this section, we examine the theoretical analog to our empirical multiplier. As in Section IV, we apply Jordà (2005)'s direct projection method on our simulated data. Specifically, we calculate the multiplier as a regression of the logarithm of regional output on its first three lags and on the logarithm of shocks to regional public investment with state and time fixed effects. ${ }^{29}$ We then compute an impulse response by stepping the dependent variable ahead through time and running the regression keeping the independent variables the same. The dynamic response of the multiplier is given by the series of coefficient estimates on public investment multiplied by the ratio of output to public investment in steady state.

Figure 10 reports our theoretical estimate of the dynamic output multiplier in our baseline model. The figure shows that the path of the multiplier follows a pattern similar to the empirical one in Figure 6. The multiplier rises on impact, before falling back for 2 years, at which point it increases again and peaks around 8-9 years, then starts to decline over time. We find the peak multiplier to be slightly below 2, but the impact multiplier to be much smaller and

\footnotetext{
${ }^{29}$ We abstracted from lags of government spending since the spending shock in our simulated data is, by construction, exogenous with respect to lagged output or spending. As we documented above, our empirical results are robust to removing lags of the dependent and independent variables in the regression.
} 
closer to 0.3 , which contrasts with the data where both the impact and the peak multipliers are considerably larger.

The top two charts in Figure 11 indicate that this dynamic pattern of the output multiplier is due to a combination of the persistence of the shock and the presence of a time-to-build process of 4 years for public capital. For instance, the multiplier rises monotonically for 10 years when we increase the persistence of the shocks from 0.27 to 0.8. Similarly, absent time-to-build, the path of the multiplier is hump-shaped, peaking sooner as the public capital stock is available for production earlier.

Intuitively, in our baseline calibration, the initial increase in economic activity triggered by the rise in government spending fades away as government spending quickly declines. At that point, new public infrastructures have yet to be completed. When the new infrastructure is in place around year $t+4$ and becomes available for production, the economy's productivity increases, boosting real wages, hours worked, and investment. As a result, output rises once again.

The remaining 4 charts in Figure 11 assess the robustness of our baseline results to the different features of our model. The middle left panel considers different values of the output elasticity of public capital, clearly a crucial parameter in our analysis. While the movements in the multiplier are similar with a lower value for that elasticity $\left(\alpha_{g}=0.05\right)$, the peak multiplier is roughly halved. Interestingly, our methodology correctly predicts the absence of a second increase in output when government spending is unproductive $\left(\alpha_{g}=0\right)$. Overall, we find it reassuring that the direct projection method is able to clearly distinguish between frameworks.

The degree to which goods in the two regions are substitutable also affects the size of the output multiplier, as indicated in the middle right panel of Figure 11. In the longer run, greater goods substitutability leads to higher multiplier, as cheaper goods resulting from the increase productive capacity of the economy can more easily be exported. The reverse is true initially since government spending has yet to boost the productive capacity of the economy, and the innovation to government spending operates like a standard demand shock in that case. As a result, lower goods substitutability across regions boosts the multiplier, as there is less "leakage" to the other region. The bottom left panel of Figure 11 also shows that introducing complementarities between consumption and hours worked in households preferences push the path of the multiplier up, but that the effect is relatively muted in our model. 
As discussed in Section II, an important aspect of the federal-aid highway program is that states are required to finance about 20 percent of the federal-aid highway projects. This introduces important fiscal aspects, as nearly all states have budget balance requirements and must therefore either increase tax revenues or cut spending to pay for the funds necessary to have access to federal grants. This is an important issue, since changes in local fiscal policy will not be differenced out using our approach, contrary to changes in fiscal policy at the federal level. In the following exercise, we assume that regional governments levy local consumption taxes to pay for financing 20 percent of the cost of federal-aid infrastructure projects, as well as their own infrastructure spending. We also assume that the local consumption tax rate is fixed to 5 percent.

We report the results of this exercise in the bottom right panel of Figure 11. The chart shows that introducing local fiscal policy has an important effect on the size of the multiplier, reducing it significantly over longer horizons. This reflects the fact that to finance 20 percent of federal infrastructure projects, local governments must decrease their own infrastructure spending to the extent that any increase in economic activity coming from the increased government spending is insufficient to boost government revenues enough to cover this cost. Therefore, the contraction of local infrastructure spending partly offsets the effect of federal spending, which accounts for the lower multiplier in the longer run. Similar issues have been emphasized recently by Cogan and Taylor (2010) in their critique of the fiscal stimulus package of 2009.

In closing, we note that aggregate multipliers can be quite different from the local multipliers that our methodology is meant to measure, since they will also include effects related to national fiscal and monetary policies. Applying the direct projections method to a population

weighted average of the two regions' output and spending shocks, we find the aggregate multiplier to be -0.14 on impact and 1.1 at its peak, significantly lower than our baseline results. However, these results will necessarily depend on the particular forms that fiscal and monetary policies are assumed to take.

\section{Concluding Remarks}

This paper analyzed the dynamic economic effects of public infrastructure investment. The prior literature on dynamic fiscal multipliers generally has shied away from studying this type of 
government spending because of several unique and challenging features of public infrastructure investment. First, how much and where the public sector invests in infrastructure often is a complicated, partially-decentralized process. In the United States and many other countries, infrastructure investment is administered primarily by lower-level governments, though the federal government provides much of the funding.

Second, infrastructure investment typically involves long implementation lags between when funding decisions are made - hence when agents may begin acting on the knowledge of forthcoming spending - and when actual government outlays show up. This feature makes the standard measure of government spending, outlays, particularly unsuited for the purpose of identifying shocks to government infrastructure investment.

Third, and related, in order to give agents (especially local governments and private contractors) a sense of how much infrastructure funding will be available down the road, federal governments often lay out the levels of nationwide funding and/or the mechanism by which that funding is distributed geographically for several years in advance. This raises the possibility that government infrastructure spending could have macroeconomic effects even before the exact distribution of infrastructure funding is known, and potentially well before actual infrastructure production begins.

Finally, a defining characteristic of government infrastructure investment is that it is at least intended to increase the economic efficiency or productivity of the private sector. Productivity-enhancing government spending should have different macroeconomic effects than other types of government spending. For instance, the standard Neoclassical effect of increased government spending leading households to increase labor supply as they recognize the burden that spending has on the government's budget constraint is potentially offset if agents also recognize the positive wealth generated by the resulting productivity gains.

Given these unique features of public infrastructure investment, our paper utilized the institutional details behind public highway spending in the United States. Many aspects of the institutional mechanism behind how federal highway funds are distributed to U.S. states allow us both to avoid the potential pitfalls posed by the features above and to turn them to our advantage in providing strong identification of exogenous shocks to infrastructure spending. In particular, federal funds are distributed to states based on strict formulas which are set many years in 
advance and make use of formula-factor data that are several years old, making these distributions exogenous with respect to current local economic conditions.

Furthermore, rather than simply use changes in these distributions directly as a measure of spending shocks, we constructed forecasts of these distributions based on information available to agents in the years prior to the distributions. We measured spending shocks as changes between last year and this year in the expected present value of highway spending from this year forward in a given state.

Using these shocks to estimate dynamic panel regressions following the direct projections approach of Jorda (2005), we found that highway spending shocks positively affect GDP at two specific horizons. There is a significant impact in the first couple of years and then a larger second-round effect after six to eight years. Yet, we find no permanent effect, as GDP is back to pre-shock levels after ten years. The multipliers that we calculate from these IRFs are large, roughly 3 on impact and even larger six to eight years out. Other estimates of local fiscal multiplier tend to be between 1 and 2. In an extension, we found that the initial impact occurs only for shocks in recessions, while later effects are not statistically different between recessions and expansions.

A natural hypothesis is that the direct channel by which federal highway funding to a local area affects local economic activity is that federal highway grants lead local governments to spend more on highways. We confirmed that, at least in our data sample, there does appear to be a strong, equi-proportional effect of federal highway grants on state government road construction spending.

In the final part of the paper, we used a theoretical framework to interpret our empirical findings. We looked at the multiplier in an open economy model with productive public capital in which states receive federal funds for infrastructure investment calibrated to capture the institutional framework of highway funding in the United States. Applying the local projection method to our simulated data, we found that the impulse response of output to a shock in public infrastructure spending follows a very similar pattern to that we estimated empirically. However, magnitude of the multipliers coming out of our simulated data are smaller than those implied by our empirical impulse responses. One possible reason, suggested by our empirical finding that the impact multiplier only occurs for shocks during a recession, is that our model abstracts from important nonlinearities that cause cycle-dependent heterogeneity in the multiplier. Developing 
non-linear general equilibrium models capable of yielding such cycle-dependent multipliers is clearly a critical area for future research.

\section{References}

Acconcia, A., G. Corsetti, and S. Simonelli (2011). "Mafia and Public Spending: Evidence on the Fiscal Multiplier from a Quasi-Experiment,” CEPR Discussion Paper No. 8305.

Aschauer, David (1989). “Is Public Expenditure Productive?” Journal of Monetary Economics, 23, pp. 177-200.

Auerbach, Alan J., and Y. Gorodnichenko (2011a). "Measuring the Output Responses to Fiscal Policy," American Economic Journal: Economic Policy, forthcoming.

Auerbach, Alan J., and Yuriy Gorodnichenko (2011b). "Fiscal Multipliers in Recession and Expansion,” NBER Working Paper \#17447.

Barro, R.J., and C.J. Redlick (2011). “Macroeconomic Effects from Government Purchases and Taxes,” Quarterly Journal of Economics, 126(1), pp. 51-102.

Baxter, Marianne, and Robert G. King (1993). "Fiscal Policy in General Equilibrium,” American Economic Review, Vol. 83, pp. 315-334.

Blanchard, O., and R. Perotti (2002). “An Empirical Characterization of the Dynamic Effects of Changes in Government Spending,” Quarterly Journal of Economics, 117(4), pp. 1329-1368.

Burnside, C., M. Eichenbaum, and J. Fisher (2004). “Fiscal Shocks and their Consequences,” Journal of Economic Theory 115, pp. 89-117.

Calvo, Guillermo A. (1983). "Staggered prices in a utility-maximizing framework," Journal of Monetary Economics 12(3), pp. 383-398

Chandra, A. and E. Thompson, (2000). “Does Public Infrastructure Affect Economic Activity? Evidence from the Rural Interstate Highway System,” Regional Science and Urban Economics 30, pp. 457-490.

Chodorow-Reich, Gabriel, Laura Feiveson, Zachary Liscow, and William Gui Woolston (forthcoming).

"Does State Fiscal Relief During Recessions Increase Employment? Evidence from the American Recovery and Reinvestment Act.” American Economic Journal: Economic Policy.

Cogan, John F., and John B. Taylor (2010). "What the Government Purchases Multiplier Actually Multiplied in the 2009 Stimulus Package,” NBER Working Paper 16505.

Conley, Timothy G., and William Dupor (2011). “The American Recovery and Reinvestment Act: Public Sector Jobs Saved, Private Sector Jobs Forestalled,” mimeo, Ohio State University. 
Corsetti, G., K. Kuester, and G. Muller (2011). "Floats, Pegs and the Transmission of Fiscal Policy,” CEPR Working Paper No.8180.

Edelberg, W., M. Eichenbaum, and J.D. Fisher (1999). "Understanding the Effects of a Shock to Government Purchases,” Review of Economic Dynamics, 2, 166-206.

Fernald, John (1999). "Roads to Prosperity? Assessing the Link between Public Capital and Productivity,” American Economic Review, June 1999, 619-638.

Feyrer, James, and Bruce Sacerdote (2011). “Did the Stimulus Stimulate? Real Time Estimates of the Effects of the American Recovery and Reinvestment Act,” NBER Working Paper No. 16759.

Fishback, P., and V. Kachanovskaya (2010). "In Search of the Multiplier for Federal Spending in the States During the New Deal,” NBER Working Paper No.16561.

Fisher, J.D.M., and R. Peters (2010). “Using Stock Returns to Identify Government Spending Shocks,” Economic Journal, 120(544), 414-436.

Giavazzi, Francesco, and Michael McMahon (2012). “The Household Effects of Government Spending,” Mimeo, University of Warwick.

Greenwood, J., Z. Hercowitz, and G. W. Huffman (1988). "Investment, Capacity Utilization and the Real Business Cycle,” American Economic Review, 78(3), pp. 402-417.

Holtz-Eakin, D., (1994). “Public-sector Capital and the Productivity Puzzle,” Review of Economic and Statistics 76(1), 12-21.

Ilzetzki, E., E. Mendoza, and C. Végh (2010). “How Big (Small?) are Fiscal Multipliers?,” NBER Working Paper No. 16479.

Jordà, Oscar (2005). “Estimation and Inference of Impulse Responses by Local Projections,” American Economic Review, Vol. 95(1), pp. 161-182.

Knight, Brian (2002). "Endogenous Federal Grants and Crowd-out of State Government Spending: Theory and Evidence from the Federal Highway Program.” American Economic Review, Vol. 92(1), pp. 71-92.

Leeper, Eric M., Todd B. Walker, Shu Chun Susan Yang (2009), “Fiscal Foresight and Information Flows,” NBER Working Paper 14630.

Leeper, Eric M., Todd B. Walker, Shu Chun Susan Yang (2010), “Government Investment and Fiscal Stimulus,” Journal of Monetary Economics 57, 1000-1012. 
Leigh, Andrew, and Christine Neil (2011), "Can national infrastructure spending reduce local unemployment? Evidence from an Australian roads program,” Economics Letters 113, pp. 150153.

Lutz, Byron (2010). “Taxation with Representation: Intergovernmental Grants in a Plebiscite Democracy.” Review of Economics and Statistics, vol. 92(2), pp. 316-332.

Monacelli, T., and R. Perotti (2008), "Fiscal Policy, Wealth Effects, and Markups," NBER Working Paper No. 14584.

Mountford, A., and H. Uhlig (2009). "What are the Effects of Fiscal Policy Shocks?,” Journal of Applied Econometrics, 24(6), pp. 960-992.

Morrison, Catherine J., and Amy Ellen Schwartz (1996). "State Infrastructure and Productive Performance,” American Economic Review, 86(5), pp. 1095-1111.

Munnell, Alicia (1992). "Infrastructure Investment and Economic Growth.” Journal of Economic Perspectives (Fall), pp. 189-198.

Nakamura, Emi, and Jon Steinsson (2011). "Fiscal Stimulus in a Monetary Union: Evidence from U.S. Regions,” unpublished manuscript, Columbia University.

Parker, J. A. (2011). “On Measuring the Effects of Fiscal Policy in Recessions.” Journal of Economic Literature, 49(3), 703-718.

Pereira, Alfredo R. (2000). “Is All Public Capital Created Equal?,” Review of Economics and Statistics 82(3), 513-518.

Perotti, R. (2004). “Public Investment: Another (different) Look,” mimeo, Università Bocconi.

Perotti, R. (2007). “In Search of the Transmission Mechanism of Fiscal Policy,” NBER Working Paper No. 13143.

Ramey, V.A. (2011a). “Identifying Government Spending Shocks: It’s all in the Timing,” Quarterly Journal of Economics 126(1), 1-50.

Ramey, V.A. (2011b). “Can Government Purchases Stimulate the Economy?” Journal of Economic Literature, 49(3), 673-685.

Ramey, V.A., and M.D. Shapiro (1998). “Costly Capital Reallocation and the Effects of Government Spending,” Carnegie-Rochester Conference Series on Public Policy, 48(1), 145-194.

Shoag, D. (2010). “The Impact of Government Spending Shocks: Evidence on the Multiplier from State Pension Plan Returns,” Working Paper, Harvard University. 
Suarez Serrato, Juan C., and Phillippe Wingender (2010). "Estimating Local Fiscal Multipliers," unpublished manuscript, University of California, Berkeley.

Stock, J.H.; Wright, J.H.; and Yogo, M. (2002). "A survey of weak instruments and weak identification in generalized method of moments” Journal of Business \& Economic Statistics, Vol. 20(4): pp. 518.

Uhlig, H., (2010). “Some Fiscal Calculus,” The American Economic Review: Papers and Proceedings 100(2), 30-34.

Wilson, D. J. (2011). "Fiscal Spending Jobs Multipliers: Evidence from the 2009 American Recovery and Reinvestment Act," American Economic Journal: Economic Policy, forthcoming. 


\section{Appendix A}

\section{Apportionment Mechanism for FHWA Grants}

\section{Sources:}

FHWA (2005), “Analysis of the Conference Report to H.R.3 as filed on 7/28/05

(RTA-000-1664A).”

URL as of 11/3/2011: http://www.fhwa.dot.gov/safetealu/fundtables.htm

FHWA (1999), “Financing Federal-Aid Highways”, Publication No. FHWA-PL-99-015.

FHWA (2007), “Financing Federal-Aid Highways”, Publication No. FHWA-PL-07-017.

Bureau of Transportation Statistics (1992), “Intermodal Surface Transportation Efficiency Act of 1991 - Summary”

TEA-21, FY1998-2003 (continued through 2004 via continuing resolutions)

Step 1:

Each individual FHWA program's national budget authorization is provisionally apportioned to states based on formula factors, conditional on a minimum apportionment share of $0.5 \%$ :

$$
A_{p i}^{\prime}=A_{p}\left\{\min \left[f_{p}\left(\frac{z_{p i}^{1}}{z_{p}^{1}}, \frac{z_{p i}^{2}}{z_{p}^{2}}, \ldots\right), 0.005\right]\right\}
$$

for each program p and state i. z denotes formula factors (e.g., highway lane-miles). "Primes” on variables indicate that they are provisional, not final, values.

\section{Step 2:}

Calculate provisional total FHWA apportionment for each state:

$$
A_{i}^{\prime}=\sum_{p} A_{p i}
$$


Step 3:

Apply "Minimum Guarantee" constraint, which ensures that each state receives a minimum return, $\mathrm{R}$, on its contribution to the Highway Trust Fund (HTF):

$$
A_{i}=\max \left[A_{i}^{\prime}, R H_{i}\right]
$$

where $\mathrm{H}_{\mathrm{i}}$ is state $i$ 's contribution to the HTF. $\mathrm{R}$ is $90.5 \%$ during all TEA-21 years. Amounts required to satisfy the minimum-guarantee $\left(A_{i}-A_{i}^{\prime}\right)$ come out of a separate Congressional appropriation. That is, it does NOT lower the apportionments determined by steps 1 and 2 for other states. This amount is called the Minimum Guarantee apportionment and is reported in Tables FA-4 on the FHWA Highway Statistics website.

\section{$\underline{\text { SAFETEA-LU, FY2005-2009 (continued through FY2011 via continuing resolutions) }}$}

Steps 1 and 2 are the same as under TEA-21. In SAFETEA-LU, the Minimum Guarantee program (Step 3) is replaced with the "Equity Bonus” program. The Equity Bonus program also

imposes a minimum guaranteed return, R, on contributions to the HTF (though now R varies by year: $\mathrm{R}=90.5 \%$ in $2005-6,91.5 \%$ in 2007 , and 92\% in 2008-9), but also imposes two additional constraints. First, for states satisfying certain criteria, the state must receive a total FHWA apportionment share at least as great as its average share over the TEA-21 period. Second, for all states, the state must receive at least a specified percentage of its average annual apportionment $\left(T_{i}\right)$ under TEA-21. This percentage $(M)$ is $117 \%$ in 2005, 118\% in 2006, 119\% in 2007, 120\% in 2008 , and $121 \%$ in 2009.

The effect of these added constraints is to replace equation (3) with the following:

$$
A_{i}=\max \left[A_{i}^{\prime}, R H_{i}, \frac{T_{i}}{T} A_{i}^{\prime} D_{i}, M T_{i}\right],
$$

where $\mathrm{D}$ is a dummy variable indicating whether the state is one of the selected states mentioned above.

The $A_{i}-A_{i}^{\prime}$ amount is called the Equity Bonus apportionment and is reported in Table FA-4 on the FHWA Highway Statistics website. Note, however, that for years 2007 onward 
(only), the apportionments for the STP, NHS, IM, Bridge, CMAQ, and HSIP programs in Table FA-4 include the amounts those programs received out of the equity bonus and the equity bonus apportionment in Table FA-4 excludes the amounts distributed to those core programs.

\section{ISTEA, FY1992-1997}

Steps 1 and 2 are the same as under TEA-21. But in ISTEA, the Minimum Guarantee program was more complicated. In addition to getting a minimum guaranteed return, $\mathrm{R}=90.5 \%$, on contributions to the HTF, states whose return on contributions to the HTF was below $100 \%$ (“donor" states) received an additional bonus. 


\section{Appendix B}

\section{Constructing Real-time Forecasts of Expected Future Highway Funding}

Our objective is to forecast, as of the beginning of a given year $t$, the present value of current and future federal highway grants for each state, using only real-time information available at the beginning of $t$. At the beginning of year $t$, agents have the following information: (1) year $t$ apportionments (grants) in each state $i$ for each FHWA program $p$ (along with the formula factors that determine these apportionments), (2) the path of nationwide apportionment authorizations for the remaining years of the current highway authorization legislation (which typically cover a 5-6 year period), and (3) the formulas used to distribute each program's grants to states for the remainder of the current legislation. What agents do not know is the future values of the formula factors that determine the distribution of grants for the remaining years of the current legislation, nor do they know (1)-(3) above for years beyond the current legislation.

To construct real-time forecasts of future highway grants, we follow and extend the methodology used by the FHWA Office of Legislation and Strategic Planning (FHWA 2005) in its report providing forecasts, as of 2005, of apportionments by state for the years of the 20052009 SAFETEA-LU highway bill. Basically, the methodology involves assuming that a state's current formula factors (as a share of the nation), and hence the state's current share of federal grants for each of the 17 FHWA apportionment programs, are constant over the forecast horizon. (As detailed below, we treat the one-time extra apportionments from the 2009 American Recovery and Reinvestment Act as a separate program.) That is, the best guess of what the relative values of formula factors will be going forward is their current year relative values. Given apportionment shares for each program, one can then distribute to states the known nationwide totals for each program for the remaining years of the current legislation. One can then aggregate across programs to get a state's total apportionments in each of these future years.

We extend this methodology such that if one is forecasting for years beyond the current legislation, one assumes a continuation of the use of current formulas (i.e., one's best guess of the formulas to be used in future legislation is the formulas currently in use) and one assumes that nationwide apportionments by program grow with inflation from the last authorized amount in the current legislation. 
More formally, we construct real-time forecasts of future highway grants by state using the following three-step procedure:

1. Let $A_{i, p, t+s} \equiv \omega_{i, p, t+s} A_{p, t+s}$ denote state i's apportionments for program $p$ in year $t+s$, where $A_{p, t+s}$ is nationwide apportionments for program $p$ and $\omega_{i, p, t+s}$ is state i's share of those apportionments. Calculate the forecast $E_{t}\left[A_{i, p, t+s}\right]$ for all $p$ and for $s \geq 0$ by assuming that $\omega_{i, p, t+s}=\omega_{i, p, t}$ and using the known authorized levels of $A_{p, t+s}$ for year $t+s$ within the current highway legislation. (Note that, for $s=0, E_{t}\left[A_{i, p, t}\right]=A_{i, p, t}$.) For any year $t+s$ beyond the last year of the current legislation, $t+j$, assume $A_{p, t+s}=A_{p, t+j}\left(1+\pi^{e}\right)^{s-j}$, where $\pi^{e}$ is expected future inflation. We assume $\pi^{e}=0.03$.

In 2009 (and only in 2009), there was a special one-time additional amount of apportionments authorized by the American Recovery and Reinvestment Act (ARRA). We treat the ARRA as simply another program ( $p=A R R A)$. The ARRA was passed on Feb. 10, 2009 and immediately authorized the FHWA to apportion $\$ 27.5$ billion in formula grants to states (i.e., $A_{A R R A, 2009}=$ $\$ 27.5$ Billion). ${ }^{30}$ The apportionment formula was:

$$
\omega_{i, A R R A, 2009}=0.5 \times \omega_{i, S T P, 2009}+0.5 \times \omega_{i, F H W A, 2008} .
$$

That is, each state's share of the $\$ 27.5$ billion in grants was to be distributed $50 \%$ based on the apportionment formula used by the FHWA to distribute grants for the Surface Transportation Program (STP) in 2009 and 50\% based on the distribution of total FHWA grants in 2008. Thus,

$$
\begin{aligned}
& E_{t}\left[A_{i, A R R A, t+s}\right]=0 \quad \forall t \neq 2009, \forall s, \\
& E_{2009}\left[A_{i, A R R A, 2009+s}\right]=0 \quad \forall s>0, \\
& E_{2009}\left[A_{i, A R R A, 2009}\right]=\left(0.5 \omega_{i, S T P, 2009}+0.5 \omega_{i, \text { FHWA }, 2008}\right) A_{A R R A, 2009} .
\end{aligned}
$$

\footnotetext{
${ }^{30}$ States were required to obligate all ARRA funds by March 2, 2010.
} 
2. Sum across programs within state for each forecast horizon:

$$
E_{t}\left[A_{i, t+s}\right]=\sum_{p} E_{t}\left[A_{i, p, t+s}\right] \text {. }
$$

3. Calculate the present value of current and expected future highway grants:

$$
E_{t}\left[P V_{i}\right]=\sum_{s=0}^{5} \frac{E_{t}\left[A_{i, t+s}\right]}{\left(1+r_{t}\right)^{s}}+\frac{E_{t}\left[A_{i, t+5}\right]}{\left(1+r_{t}\right)^{5}} \frac{1}{\left(1-\beta_{t}\right)},
$$

where $E_{t}\left[A_{i, t+s}\right]$ is the forecast as of $t$ of apportionments (in nominal dollars) in year $t+s$ and $\beta_{t}=\left(1+\pi_{t}^{e}\right) /\left(1+r_{t}\right)$. The second term on the right hand side reflects the fact that , because highway appropriations bills cover at most 6 years ( $t$ to $t+5$ ), forecasts beyond $t+5$ simply assume perpetual continuation of $A_{i, t+5}$ (discounted by $\left(1+r_{t}\right)^{5}$ ) growing with expected future inflation of $\pi_{t}^{e}$. We measure the nominal discount rate, $r_{t}$, using a 10-year trailing average of the 10-year Treasury bond rate as of the beginning of the fiscal year $t$ (e.g., Oct. 1, 2008 is the beginning of fiscal year $t=2009$ ). The trailing average is meant to provide an estimate of the long-run expected nominal interest rate. We measure expected future inflation, $\pi_{t}^{e}$, using the median 5- or 10-year ahead inflation forecast for the first quarter of the fiscal year (fourth quarter of prior calendar year) from the Survey of Professional Forecasters (SPF). ${ }^{31}$

\section{Dealing with the Equity-Bonus/Minimum-Guarantee Apportionments}

One complication for implementing the above is that the equity-bonus/minimumguarantee apportionments are treated differently in the FHWA data tables in years prior to 2007 than they are for 2007 onward. Prior to 2007, apportionments for all programs in the FHWA highway statistics (Table FA-4) do not include any added amounts distributed to those programs from the pool of funds Congress authorizes to satisfy the equity-bonus/minimum-guarantee constraints discussed in Appendix X. For 2007 onward, however, the reported apportionments for the "core programs" (STP, NHS, IM, Bridge, CMAQ, and HSIP) include the amounts distributed from the equity-bonus/minimum-guarantee pool. Therefore, apportionments by

\footnotetext{
${ }^{31} 5$-year ahead forecasts are available in the SPF only from 2006 onward. Prior to 2006, we use the 10-year ahead forecast. The two forecasts are very similar in the data.
} 
program, $A_{i, p, t}$, from the raw FHWA data are not comparable before and after 2007. We handle this by distributing, for years prior to 2007, part of the equity-bonus/minimum-guarantee nationwide authorization to each of these core programs in proportion to their share of total FHWA authorizations for that year. This extra amount is added to the reported $A_{i, p, t}$ to get the true $A_{i, p, t}$ that we use in the steps above.

\section{Data}

Data on actual apportionments by program, state, and year $\left(A_{i, p, t}\right)$, which also are used to construct apportionment shares $\left(\omega_{i, p, t}\right)$, were obtained from FHWA Highway Statistics, Table FA-4 (various years). Data on nationwide authorizations by program and year $\left(A_{p, t+s}\right)$ for each of the three highway authorization legislations during our sample period were obtained from FHWA (1992), FHWA (1999), and FHWA (2007). 


\section{Appendix C. Data Glossary}

Format: variable_name - Data description. (Source)

BEA_employment - Total annual employment from the BEA's National Income and Product Accounts. (Haver Analytics/Bureau of Economic Analysis)

capoutlays_total - State highway agency total capital outlays, in millions of dollars. These data are obtained from the Office of Highway Policy Information's annual Highway Statistic Series publications. (Federal Highway Administration)

capoutlays_fedaid-State highway agency capital outlays on federal-aid highways, in millions of dollars. These data are obtained from the Office of Highway Policy Information's annual Highway Statistic Series publications. (Federal Highway Administration)

F_S - State government expenditures on construction of regular and toll highways, in millions of dollars. This variable is one of the components of Shighway_gross. (US Census Annual Survey of State \& Local Government Finances)

FHWA_oblig - Total federal funds obligated by the Federal Highway Administration to state governments, in millions of dollars. These data are obtained from the Office of Highway Policy Information's annual Highway Statistic Series publications, Table FA-4B, various years. Note that obligations due to grants from the 2009 American Recovery and Reinvestment Act (ARRA) ARE included in these reported totals. (Federal Highway Administration)

FHWA_apport - Federal Funds apportioned by the Federal Highway Administration to state governments, in millions of dollars. These data are obtained from the Office of Highway Policy Information's annual Highway Statistic Series publications, Table FA-4, various years. Because these data do NOT include the additional grants in 2009 from the ARRA, we add the ARRA apportionments to the 2009 total. We obtained state-level ARRA apportionments (as well as outlays) for fiscal year 2009 from the DOT's Financial and Activity Report as of Oct. 9, 2009 (which covers data through the end of fiscal year 2009) for TAFS code 69-0504, which corresponds to Highway Funding. (Federal Highway Administration and DOT)

FHWA_outlays - Total outlays (expenditures) of federal funds by the Federal Highway Administration to state governments, in millions of dollars. These data are obtained from the Office of Highway Policy Information's annual Highway Statistic Series publications, Table FA- 
3, various years. Because the totals in Table FA-3 do NOT include the additional outlays in 2009 from the ARRA, we add the ARRA outlays to the 2009 total. We obtained state-level ARRA outlays for fiscal year 2009 from the DOT’s Financial and Activity Report as of Oct. 9, 2009 (which covers data through the end of fiscal year 2009) for TAFS code 69-0504, which corresponds to Highway Funding. (Federal Highway Administration and DOT)

LNAGRA - Total nonfarm employment. The annual employment figure is the 12-month mean of monthly data over the calendar year. (Haver Analytics/BLS Establishment Survey)

population - Annual resident population (Haver Analytics/ US Census Bureau)

RealGSP_TO - Real gross domestic product by state, in millions of chained 2005 dollars. (Haver Analytics/Bureau of Economic Analysis)

Shighway_gross - State government highway expenditures, in millions of dollars. This data series is constructed from the Census Bureau's Annual Survey of State \& Local Government Finances (SLGF). It is the sum, for regular and toll highways, of state government expenditures on state government expenditures on current operations; construction capital outlays; other capital outlays; and transfers to local governments for roads. (US Census Bureau)

totaldisbursements - Total state and local government disbursements for highways, in millions of dollars. These data are obtained from the Office of Highway Policy Information's annual Highway Statistic Series publications, Table SF-2, various years. Total disbursements are the sum of capital outlays; maintenance; administration, research and planning; highway law enforcement and safety; interest payments on highway bonds; bond retirement; and transfers to local governments for roads. (Federal Highway Administration)

YPH - Real annual personal income, in millions of chained 2005 dollars. (Haver Analytics/Bureau of Economic Analysis) 
Table 1

Apportionment Formulas for Largest FHWA Programs, as of 2008

\begin{tabular}{|c|c|c|c|c|}
\hline PROGRAM & FACTORS & WEIGHT & $\begin{array}{c}\text { MINIMUM } \\
\text { APPORTIONMENT }\end{array}$ & $\begin{array}{c}\text { SHARE OF } \\
\text { TOTAL FUNDS }\end{array}$ \\
\hline Interstate Maintenance (IM) & $\begin{array}{l}\text { Interstate System lane miles } \\
\text { Vehicle miles traveled on the Interstate System } \\
\text { Annual contributions to the Highway Account of the Highway Trust Fund } \\
\text { attributable to commercial vehicles }\end{array}$ & $\begin{array}{l}33.33 \% \\
33.33 \% \\
33.33 \%\end{array}$ & $\begin{array}{l}1 / 2 \text { percent of Interstate Maintenance } \\
\text { and National Highway System } \\
\text { apportionments combined }\end{array}$ & $18.2 \%$ \\
\hline National Highway System (NHS) & $\begin{array}{l}\text { Lane miles on principal arterial routes (excluding the Interstate System) } \\
\text { Vehicle miles traveled on principal arterial routes (excluding the Interstate System) } \\
\text { Diesel fuel used on highways } \\
\text { Total lane miles on principal arterials divided by the State's total } \\
\quad \text { population }\end{array}$ & $\begin{array}{l}25 \% \\
35 \% \\
30 \% \\
10 \%\end{array}$ & $\begin{array}{l}1 / 2 \text { percent of Interstate Maintenance } \\
\text { and National Highway System } \\
\text { apportionments combined }\end{array}$ & $22.1 \%$ \\
\hline Surface Transportation Program (STP) & $\begin{array}{l}\text { Total lane miles of Federal-aid highways } \\
\text { Total vehicle miles traveled on Federal-aid highways } \\
\text { Estimated tax payments attributable to highway users paid into the Highway } \\
\text { Account of the Highway Trust Fund }\end{array}$ & $\begin{array}{l}25 \% \\
40 \% \\
35 \%\end{array}$ & $1 / 2$ percent & $23.3 \%$ \\
\hline $\begin{array}{l}\text { Bridge Replacement } \\
\text { and Rehabilitation Program (BRR) }\end{array}$ & Relative share of total cost to repair or replace deficient bridges & $100 \%$ & $1 / 4$ percent (10 percent maximum) & $14.8 \%$ \\
\hline $\begin{array}{l}\text { Congestion Mitigation and Air Quality } \\
\text { Improvement Program (CMAQ) }\end{array}$ & Weighted nonattainment and maintenance area population & $100 \%$ & $1 / 2$ percent & $6.1 \%$ \\
\hline Recreational Trails Program (RT) & $\begin{array}{l}\text { Equal shares to each eligible State } \\
\text { Nonhighway recreational fuel use during the preceding year }\end{array}$ & $\begin{array}{l}50 \% \\
50 \%\end{array}$ & None & $0.2 \%$ \\
\hline Metropolitan Planning (MP) & Urbanized area population* & $100 \%$ & $1 / 2$ percent & $0.8 \%$ \\
\hline Highway Safety Improvement Program (HSIP) & $\begin{array}{l}\text { Total lane miles of Federal-aid highways } \\
\text { Total vehicle miles traveled on Federal-aid highways } \\
\text { Number of fatalities on the National Highway system }\end{array}$ & $\begin{array}{l}33.33 \% \\
33.33 \% \\
33.33 \%\end{array}$ & $1 / 2$ percent & $3.9 \%$ \\
\hline
\end{tabular}

* Usually places of 50,000 or more persons. Definition contained in 23 U.S.S. 101(a)

Note: Main programs only. Share of total funds will not sum to $100 \%$ 
Table 2

The Implementation Lags of Highway Spending

\begin{tabular}{|c|c|c|c|}
\hline & $\begin{array}{c}\text { FHWA Obligations } \\
\beta / \mathrm{SE}\end{array}$ & $\begin{array}{c}\text { FHWA Outlays } \\
\beta / \mathrm{SE}\end{array}$ & $\begin{array}{c}\text { FHWA Outlays } \\
\beta / \mathrm{SE}\end{array}$ \\
\hline FHWA Grants & $\begin{array}{c}0.700 \\
(0.106)\end{array}$ & - & $\begin{array}{c}0.122 \\
(0.064)\end{array}$ \\
\hline FHWA Grants, Lagged 1 year & $\begin{array}{c}0.345 \\
(0.133)\end{array}$ & - & $\begin{array}{c}0.526 \\
(0.081)\end{array}$ \\
\hline FHWA Grants, Lagged 2 years & $\begin{array}{l}-0.037 \\
(0.101)\end{array}$ & - & $\begin{array}{l}0.108 \\
(0.062)\end{array}$ \\
\hline FHWA Grants, Lagged 3 years & $\begin{array}{l}-0.020 \\
(0.038)\end{array}$ & - & $\begin{array}{c}0.044 \\
(0.023)\end{array}$ \\
\hline FHWA Grants, Lagged 4 years & $\begin{array}{l}-0.016 \\
(0.036)\end{array}$ & - & $\begin{array}{c}0.058 \\
(0.022)\end{array}$ \\
\hline FHWA Grants, Lagged 5 years & - & - & $\begin{array}{c}0.053 \\
(0.016)\end{array}$ \\
\hline FHWA Grants, Lagged 6 years & - & - & $\begin{array}{c}0.063 \\
(0.015)\end{array}$ \\
\hline FHWA Grants, Lagged 7 years & - & - & $\begin{array}{c}0.021 \\
(0.015)\end{array}$ \\
\hline FHWA Obligations & - & $\begin{array}{c}0.231 \\
(0.019)\end{array}$ & - \\
\hline FHWA Obligations, Lagged 1 year & - & $\begin{array}{c}0.208 \\
(0.032)\end{array}$ & - \\
\hline FHWA Obligations, Lagged 2 years & - & $\begin{array}{c}0.112 \\
(0.021)\end{array}$ & - \\
\hline FHWA Obligations, Lagged 3 years & - & $\begin{array}{c}0.119 \\
(0.031)\end{array}$ & - \\
\hline FHWA Obligations, Lagged 4 years & - & $\begin{array}{c}0.143 \\
(0.030)\end{array}$ & - \\
\hline FHWA Obligations, Lagged 5 years & - & $\begin{array}{c}0.070 \\
(0.030)\end{array}$ & - \\
\hline FHWA Obligations, Lagged 6 years & - & $\begin{array}{l}-0.007 \\
(0.030)\end{array}$ & - \\
\hline FHWA Obligations, Lagged 7 years & - & $\begin{array}{c}0.030 \\
(0.028)\end{array}$ & - \\
\hline Year fixed effects & Yes & Yes & Yes \\
\hline State fixed effects & Yes & Yes & Yes \\
\hline Cumulative Effect & $\begin{array}{c}0.973 \\
(0.064)\end{array}$ & $\begin{array}{c}0.906 \\
(0.033)\end{array}$ & $\begin{array}{c}0.996 \\
(0.042)\end{array}$ \\
\hline $\begin{array}{l}\mathrm{N} \\
R^{2}\end{array}$ & $\begin{array}{c}784 \\
0.386\end{array}$ & $\begin{array}{c}735 \\
0.764\end{array}$ & $\begin{array}{c}735 \\
0.693\end{array}$ \\
\hline
\end{tabular}

Notes: Bold indicates significance at 10 percent level. All variables are per-capita.

Sample covers years 1993 - 2008 and all 50 states except Alaska. 
Table 3

Response of GDP to Highway Grant Shock

\begin{tabular}{|c|c|c|c|c|c|c|c|c|}
\hline $\begin{array}{l}\text { Dependent } \\
\text { Variable }\end{array}$ & $\begin{array}{c}\text { Shock Variable } \\
\beta / \mathrm{SE}\end{array}$ & $\begin{array}{c}G D P_{t-1} \\
\beta / \mathrm{SE}\end{array}$ & $\begin{array}{c}G D P_{t-2} \\
\beta / \mathrm{SE}\end{array}$ & $\begin{array}{c}G D P_{t-3} \\
\beta / \mathrm{SE}\end{array}$ & $\begin{array}{c}\text { Obligations }_{t-1} \\
\beta / \mathrm{SE}\end{array}$ & $\begin{array}{c}\text { Obligationst-2 } \\
\beta / \mathrm{SE}\end{array}$ & $\begin{array}{c}\text { Obligationst-3 } \\
\beta / \mathrm{SE}\end{array}$ & $\mathrm{N}$ \\
\hline$G D P_{t}$ & $\begin{array}{c}0.012 \\
(0.005)\end{array}$ & $\begin{array}{l}1.044 \\
(0.043)\end{array}$ & $\begin{array}{c}0.001 \\
(0.079)\end{array}$ & $\begin{array}{l}-0.152 \\
(0.056)\end{array}$ & $\begin{array}{l}-0.003 \\
(0.008)\end{array}$ & $\begin{array}{c}-0.003 \\
(0.004)\end{array}$ & $\begin{array}{c}-0.002 \\
(0.006)\end{array}$ & 882 \\
\hline$G D P_{t+1}$ & $\begin{array}{c}0.014 \\
(0.008)\end{array}$ & $\begin{array}{l}1.092 \\
(0.077)\end{array}$ & $\begin{array}{l}-0.199 \\
(0.076)\end{array}$ & $\begin{array}{l}-0.112 \\
(0.087)\end{array}$ & $\begin{array}{l}-0.006 \\
(0.011)\end{array}$ & $\begin{array}{l}-0.008 \\
(0.007)\end{array}$ & $\begin{array}{c}0.001 \\
(0.007)\end{array}$ & 833 \\
\hline$G D P_{t+2}$ & $\begin{array}{l}-0.008 \\
(0.008)\end{array}$ & $\begin{array}{l}0.861 \\
(0.115)\end{array}$ & $\begin{array}{l}-0.145 \\
(0.092)\end{array}$ & $\begin{array}{l}-0.055 \\
(0.093)\end{array}$ & $\begin{array}{l}-0.007 \\
(0.008)\end{array}$ & $\begin{array}{l}-0.006 \\
(0.007)\end{array}$ & $\begin{array}{l}-0.000 \\
(0.013)\end{array}$ & 784 \\
\hline$G D P_{t+3}$ & $\begin{array}{l}-0.015 \\
(0.010)\end{array}$ & $\begin{array}{c}0.661 \\
(0.112)\end{array}$ & $\begin{array}{l}-0.125 \\
(0.076)\end{array}$ & $\begin{array}{c}0.018 \\
(0.111)\end{array}$ & $\begin{array}{l}-0.005 \\
(0.009)\end{array}$ & $\begin{array}{l}-0.012 \\
(0.011)\end{array}$ & $\begin{array}{c}0.005 \\
(0.016)\end{array}$ & 735 \\
\hline$G D P_{t+4}$ & $\begin{array}{l}-0.007 \\
(0.009)\end{array}$ & $\begin{array}{c}0.451 \\
(0.124)\end{array}$ & $\begin{array}{c}0.037 \\
(0.078)\end{array}$ & $\begin{array}{l}-0.032 \\
(0.101)\end{array}$ & $\begin{array}{l}-0.007 \\
(0.012)\end{array}$ & $\begin{array}{l}-0.003 \\
(0.012)\end{array}$ & $\begin{array}{c}0.007 \\
(0.017)\end{array}$ & 686 \\
\hline$G D P_{t+5}$ & $\begin{array}{c}0.008 \\
(0.008)\end{array}$ & $\begin{array}{c}0.396 \\
(0.121)\end{array}$ & $\begin{array}{l}-0.009 \\
(0.104)\end{array}$ & $\begin{array}{l}-0.009 \\
(0.095)\end{array}$ & $\begin{array}{l}0.006 \\
(0.013)\end{array}$ & $\begin{array}{l}0.000 \\
(0.014)\end{array}$ & $\begin{array}{l}-0.006 \\
(0.016)\end{array}$ & 637 \\
\hline$G D P_{t+6}$ & $\begin{array}{c}0.026 \\
(0.009)\end{array}$ & $\begin{array}{c}0.297 \\
(0.112)\end{array}$ & $\begin{array}{c}0.092 \\
(0.086)\end{array}$ & $\begin{array}{l}-0.089 \\
(0.104)\end{array}$ & $\begin{array}{c}0.016 \\
(0.016)\end{array}$ & $\begin{array}{l}-0.010 \\
(0.013)\end{array}$ & $\begin{array}{l}-0.004 \\
(0.016)\end{array}$ & 588 \\
\hline$G D P_{t+7}$ & $\begin{array}{c}0.024 \\
(0.008)\end{array}$ & $\begin{array}{l}0.345 \\
(0.130)\end{array}$ & $\begin{array}{l}-0.152 \\
(0.072)\end{array}$ & $\begin{array}{c}0.063 \\
(0.093)\end{array}$ & $\begin{array}{c}0.007 \\
(0.016)\end{array}$ & $\begin{array}{l}-0.007 \\
(0.014)\end{array}$ & $\begin{array}{l}-0.003 \\
(0.017)\end{array}$ & 539 \\
\hline$G D P_{t+8}$ & $\begin{array}{c}0.011 \\
(0.005)\end{array}$ & $\begin{array}{c}0.223 \\
(0.127)\end{array}$ & $\begin{array}{l}-0.097 \\
(0.103)\end{array}$ & $\begin{array}{c}0.100 \\
(0.088)\end{array}$ & $\begin{array}{l}-0.002 \\
(0.016)\end{array}$ & $\begin{array}{l}-0.008 \\
(0.016)\end{array}$ & $\begin{array}{c}0.004 \\
(0.017)\end{array}$ & 490 \\
\hline$G D P_{t+9}$ & $\begin{array}{l}0.001 \\
(0.006)\end{array}$ & $\begin{array}{c}0.150 \\
(0.115)\end{array}$ & $\begin{array}{l}-0.074 \\
(0.076)\end{array}$ & $\begin{array}{l}0.106 \\
(0.088)\end{array}$ & $\begin{array}{l}-0.009 \\
(0.018)\end{array}$ & $\begin{array}{c}0.002 \\
(0.014)\end{array}$ & $\begin{array}{c}0.002 \\
(0.015)\end{array}$ & 441 \\
\hline$G D P_{t+10}$ & $\begin{array}{l}-0.005 \\
(0.006)\end{array}$ & $\begin{array}{c}0.105 \\
(0.141)\end{array}$ & $\begin{array}{l}-0.100 \\
(0.153)\end{array}$ & $\begin{array}{c}0.130 \\
(0.098)\end{array}$ & $\begin{array}{c}0.001 \\
(0.018)\end{array}$ & $\begin{array}{c}0.001 \\
(0.015)\end{array}$ & $\begin{array}{c}0.004 \\
(0.015)\end{array}$ & 392 \\
\hline
\end{tabular}

Notes: Bold indicates significance at 10 percent level. All regressions include state and year fixed effects.

Sample covers years 1993 - 2010 and all 50 states except Alaska. Variables are in logs. 
Table 4

GDP Impulse Response, By Year

Panel A. Total Highway Grant Shock

\begin{tabular}{|c|c|c|}
\hline Year & $\begin{array}{c}\text { Contemporaneous } \\
\beta / \mathrm{SE}\end{array}$ & $\begin{array}{c}\text { One-Year Ahead } \\
\beta / \mathrm{SE}\end{array}$ \\
\hline 1993 & $\begin{array}{l}.014 \\
(.019)\end{array}$ & $\begin{array}{c}.002 \\
(.027)\end{array}$ \\
\hline 1994 & $\begin{array}{l}.000 \\
(.053)\end{array}$ & $\begin{array}{l}.055 \\
(.075)\end{array}$ \\
\hline 1995 & $\begin{array}{l}.009 \\
(.019)\end{array}$ & $\begin{array}{l}.005 \\
(.027)\end{array}$ \\
\hline 1996 & $\begin{array}{l}.011 \\
(.013)\end{array}$ & $\begin{array}{l}.022 \\
(.019)\end{array}$ \\
\hline 1997 & $\begin{array}{l}-.050 \\
(.035)\end{array}$ & $\begin{array}{l}-.048 \\
(.049)\end{array}$ \\
\hline 1998 & $\begin{array}{l}.012 \\
(.012)\end{array}$ & $\begin{array}{l}.023 \\
(.017)\end{array}$ \\
\hline 1999 & $\begin{array}{l}-.055 \\
(.012)\end{array}$ & $\begin{array}{l}.003 \\
(.076)\end{array}$ \\
\hline 2000 & $\begin{array}{l}.146 \\
(.073)\end{array}$ & $\begin{array}{l}.233 \\
(.102)\end{array}$ \\
\hline 2001 & $\begin{array}{l}-.221 \\
(.107)\end{array}$ & $\begin{array}{l}-.213 \\
(.151)\end{array}$ \\
\hline 2002 & $\begin{array}{l}-.057 \\
(.086)\end{array}$ & $\begin{array}{l}-.125 \\
(.121)\end{array}$ \\
\hline 2003 & $\begin{array}{l}-.009 \\
(.034)\end{array}$ & $\begin{array}{l}-.041 \\
(.048)\end{array}$ \\
\hline 2004 & $\begin{array}{l}.041 \\
(.096)\end{array}$ & $\begin{array}{l}.129 \\
(.135)\end{array}$ \\
\hline 2005 & $\begin{array}{l}.011 \\
(.019)\end{array}$ & $\begin{array}{l}-.001 \\
(.027)\end{array}$ \\
\hline 2006 & $\begin{array}{l}-.077 \\
(.039)\end{array}$ & $\begin{array}{l}-.104 \\
(.056)\end{array}$ \\
\hline 2007 & $\begin{array}{l}.035 \\
(.040)\end{array}$ & $\begin{array}{l}.045 \\
(.057)\end{array}$ \\
\hline 2008 & $\begin{array}{l}-.040 \\
(.072)\end{array}$ & $\begin{array}{l}-.162 \\
(.101)\end{array}$ \\
\hline 2009 & $\begin{array}{l}.110 \\
(.028)\end{array}$ & $\begin{array}{l}.122 \\
(.040)\end{array}$ \\
\hline 2010 & $\begin{array}{l}-.007 \\
(.063)\end{array}$ & $\begin{array}{l}- \\
-\end{array}$ \\
\hline
\end{tabular}

Panel B. ARRA Grant Shock vs. non-ARRA Grant Shock

\begin{tabular}{lcc} 
Year & Contemporaneous & One-Year Ahead \\
& $\beta / \mathrm{SE}$ & $\beta / \mathrm{SE}$ \\
\hline \hline 2009 ARRA & $\mathbf{. 0 3 3}$ & $\mathbf{. 0 3 2}$ \\
2009 Non-ARRA & $\mathbf{( . 0 0 6 )}$ & $\mathbf{( . 0 0 9 )}$ \\
& $\mathbf{. 0 6 7}$ & $\mathbf{. 0 8 3}$ \\
2010 ARRA & $\mathbf{( . 0 2 9 )}$ & $\mathbf{( . 0 4 1 )}$ \\
& -.004 & - \\
2010 Non-ARRA & $(.004)$ & - \\
& -.016 & -
\end{tabular}

Notes: Bold indicates significance at 10 percent level. All variables are per-capita. 
Figure 1

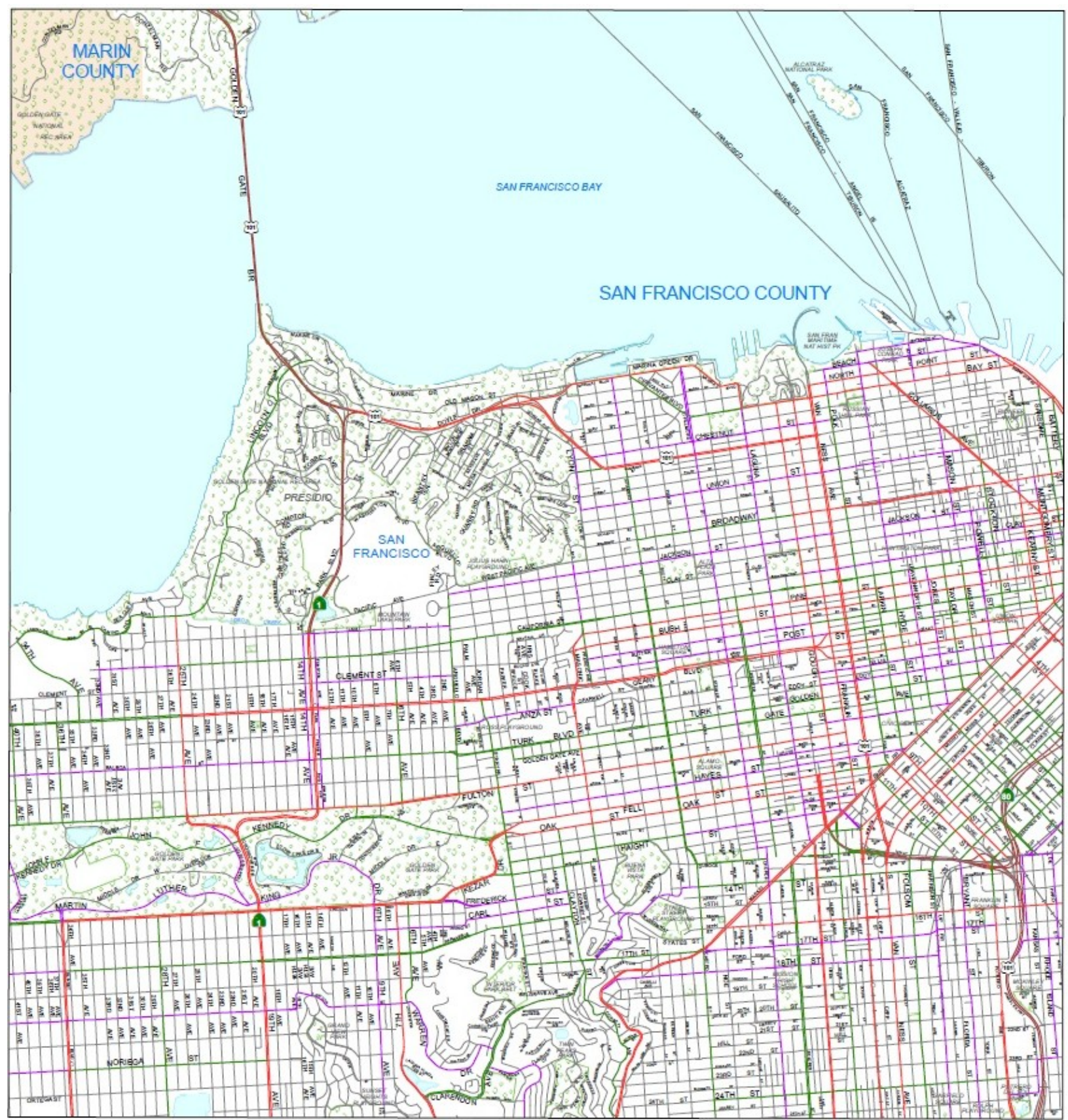

Federal-Aid Highways

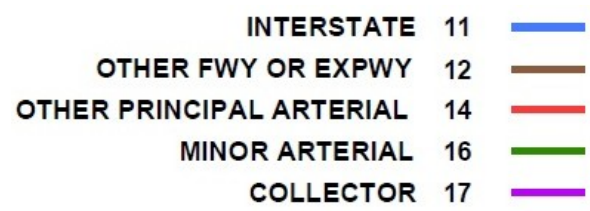

Non Federal-Aid Highways

LOCAL 19 
Figure 2

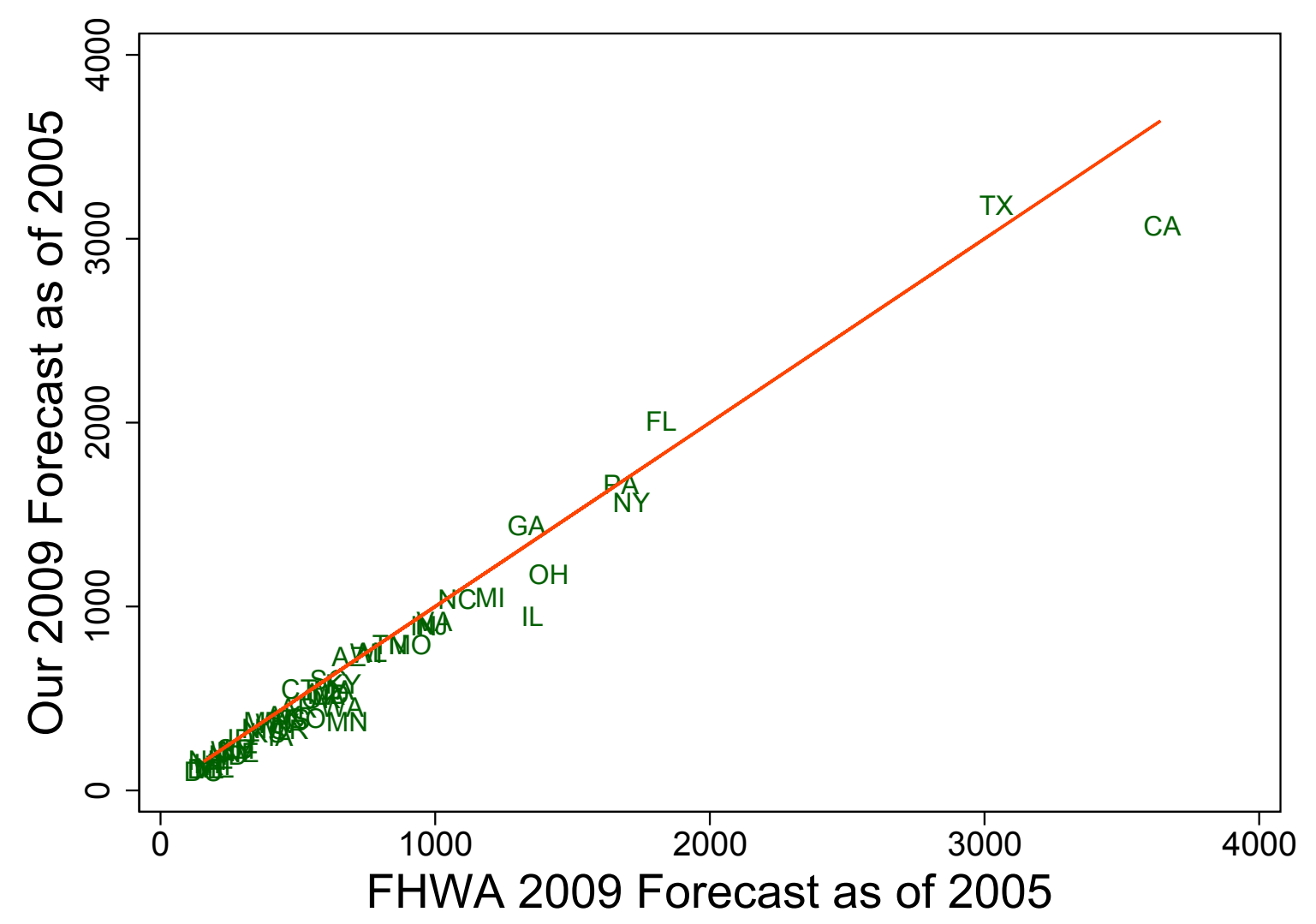




\section{Figure 3}

Actual Grants p.c. vs 4-year-ahead Forecasts

ISTEA

(1992 - 1997)

TEA - 21

(1998 - 2003)

(2005 - 2009)
Within - Bill
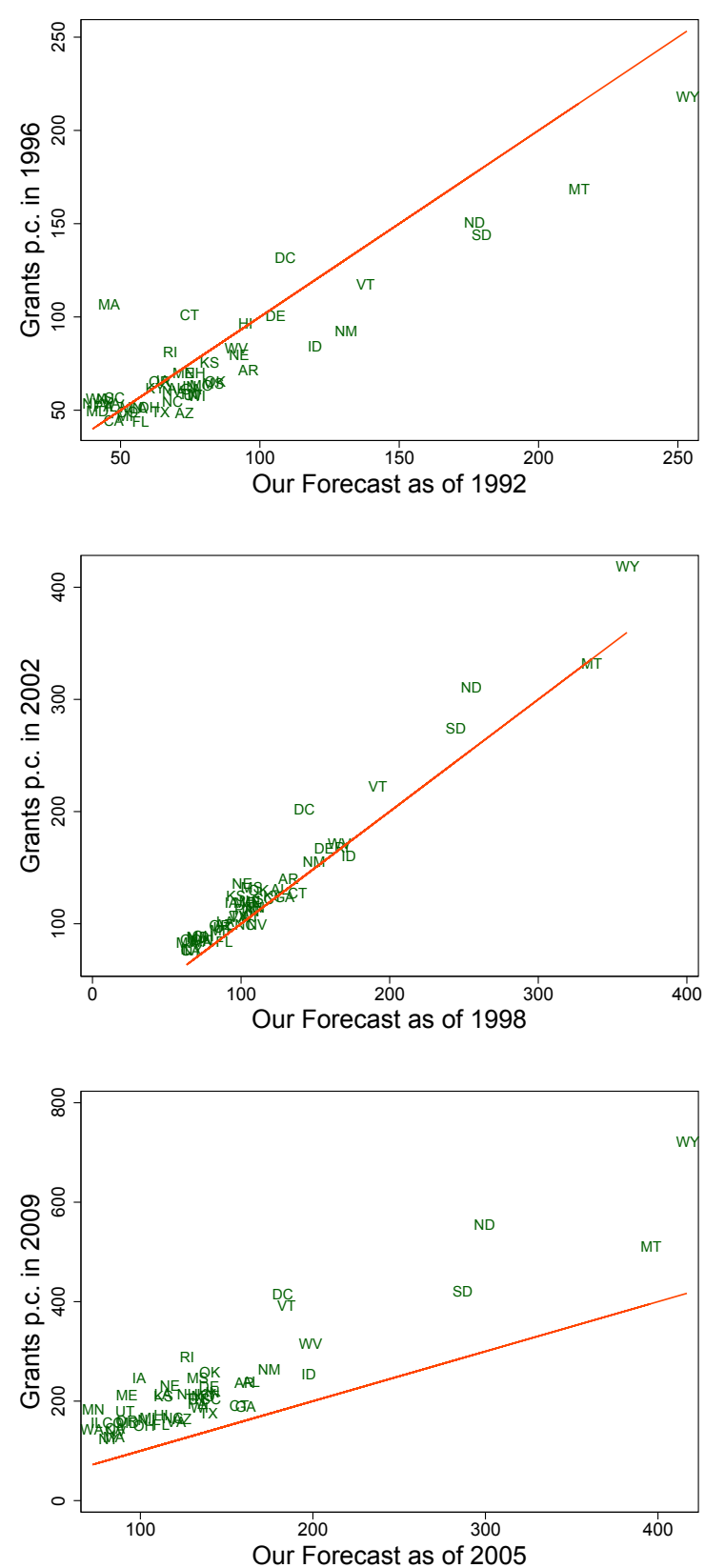

Across - Bill
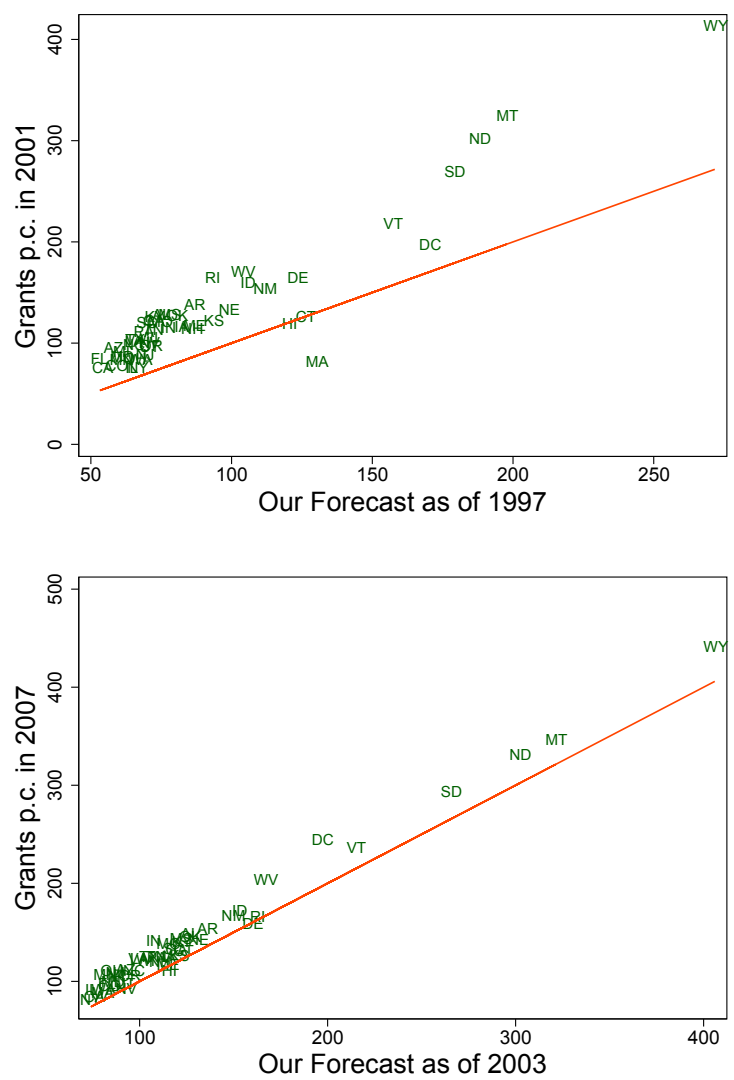
Figure 4

Unanticipated Change in Expected Present Value of Highway Grants

Panel A

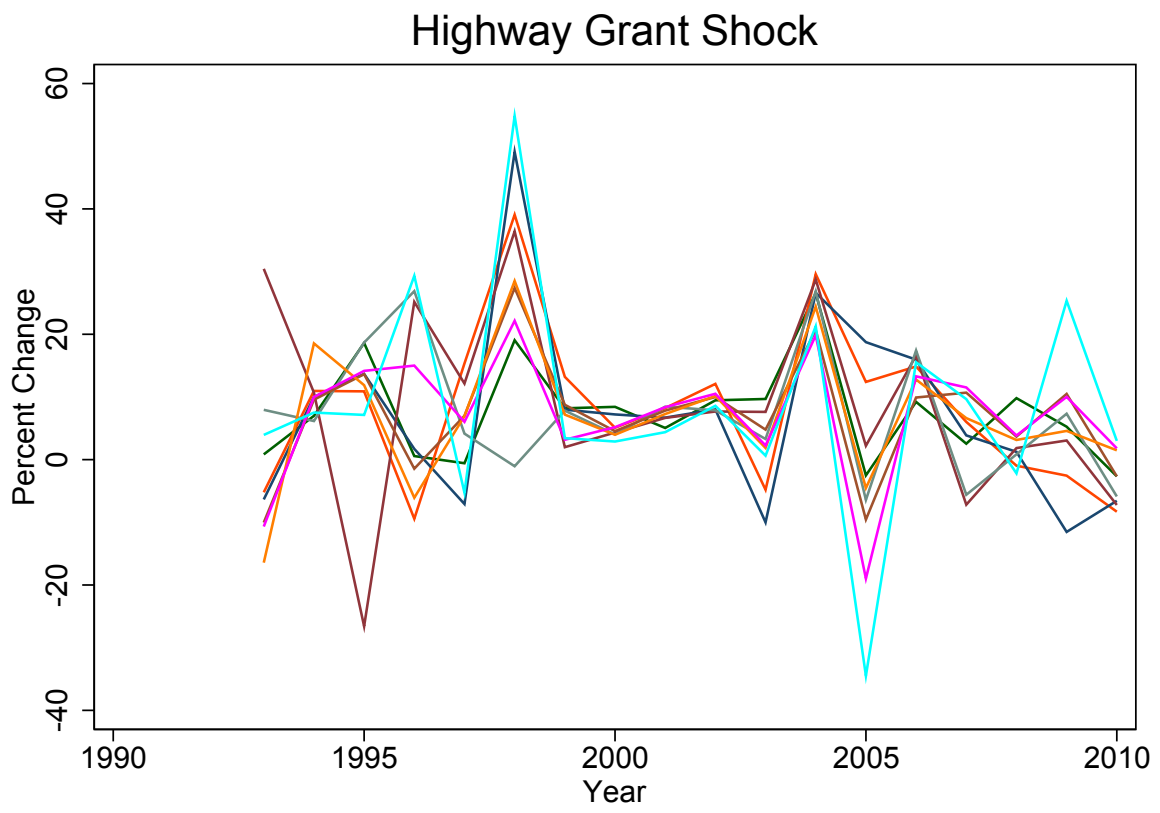

Panel B

Forecast Error
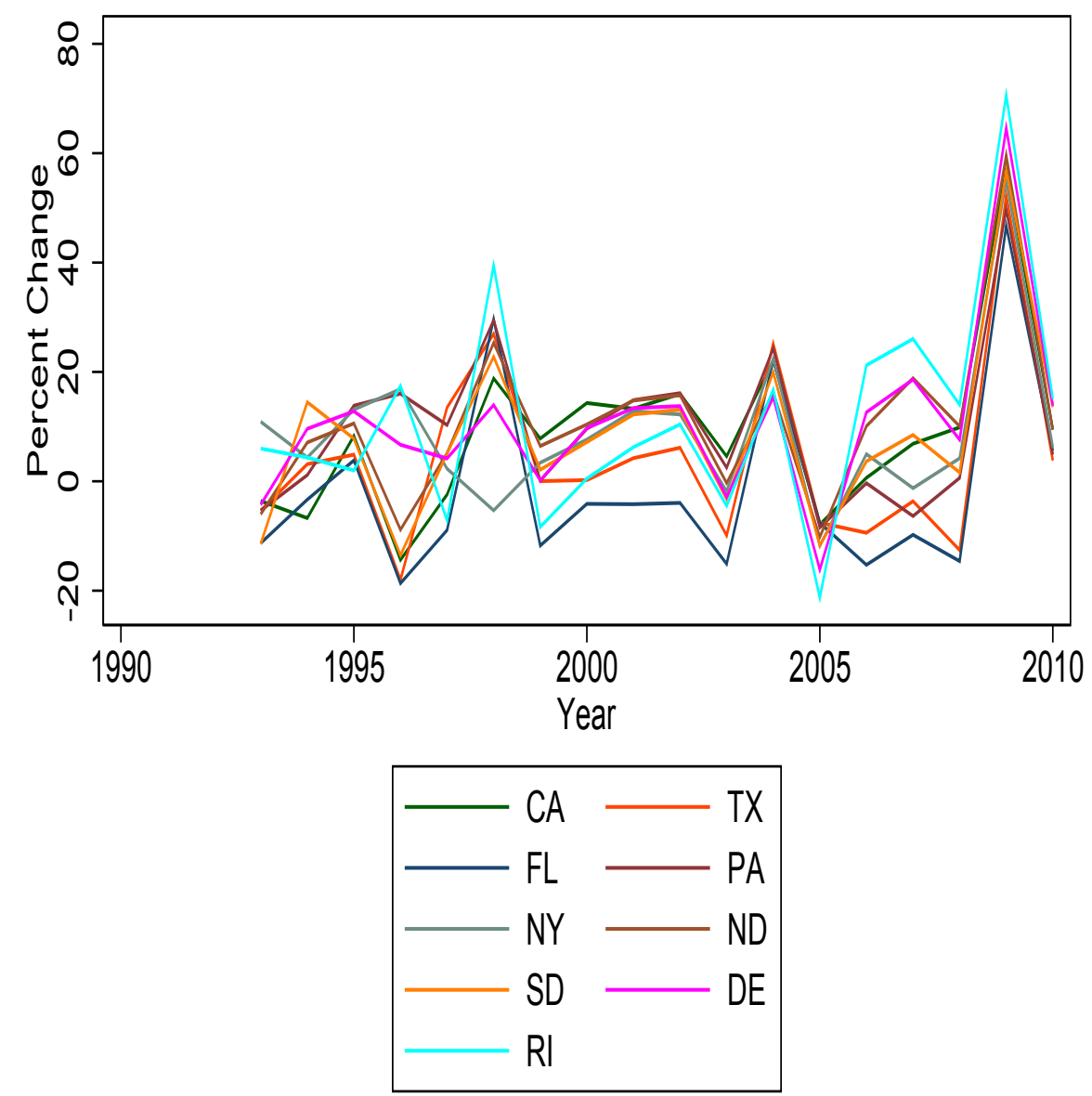


\section{Figure 5}

Panel A: Impulse Response of State GDP to Highway Grant Shock

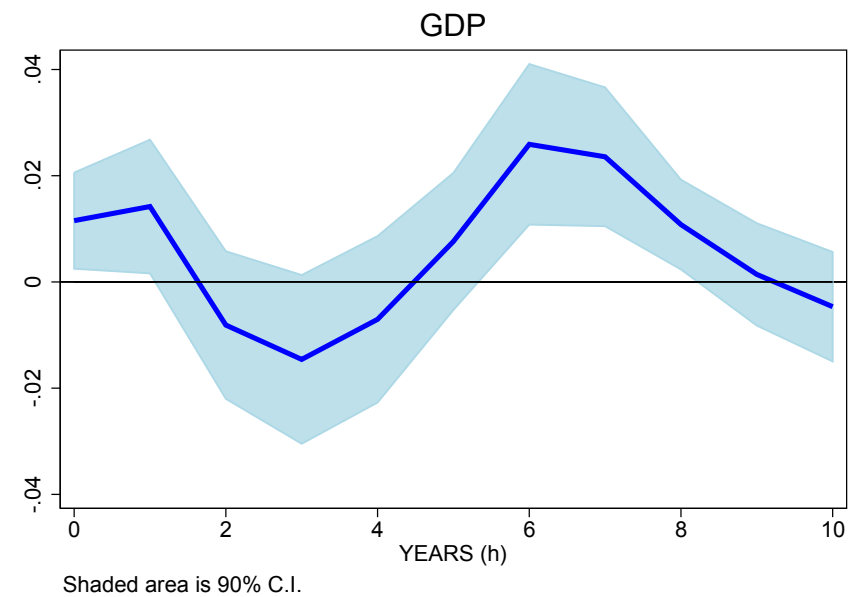

Panel B: Shock Based on Forecast Errors

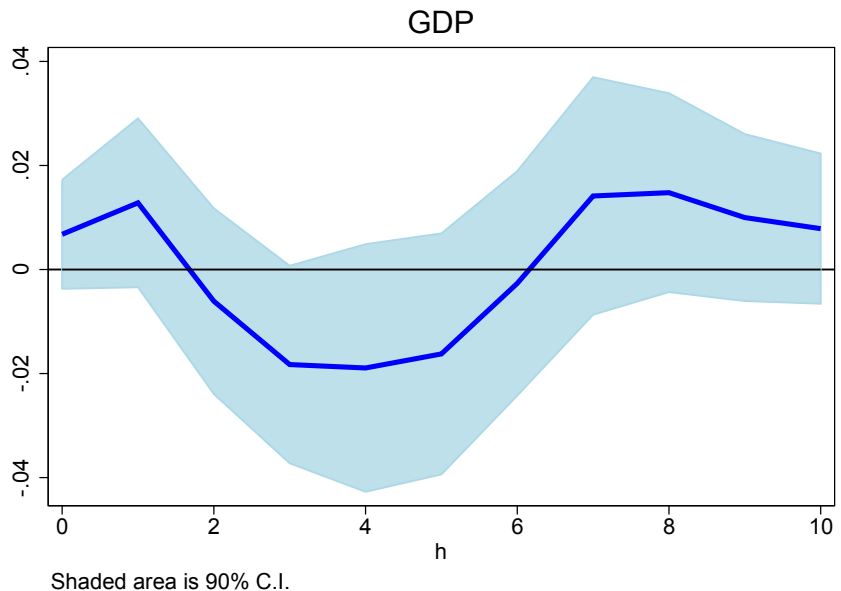

Panel C: Shock Based on Actual Grants

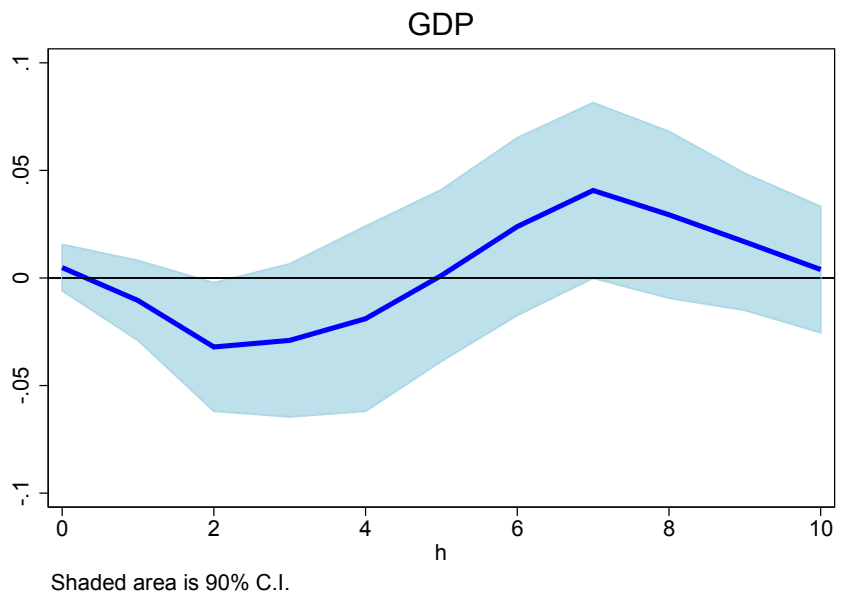

Notes: Each point is coefficient on shock from regressing $G D P_{t+h}$ on $G D P_{t-1} \ldots G D P_{t-3}$, obligations $s_{t-1} \ldots$ obligations $s_{t-3}$, and shock $_{t}$.

GDP measured in logs.

Regressions control for state and year fixed effects. 


\section{Figure 6}

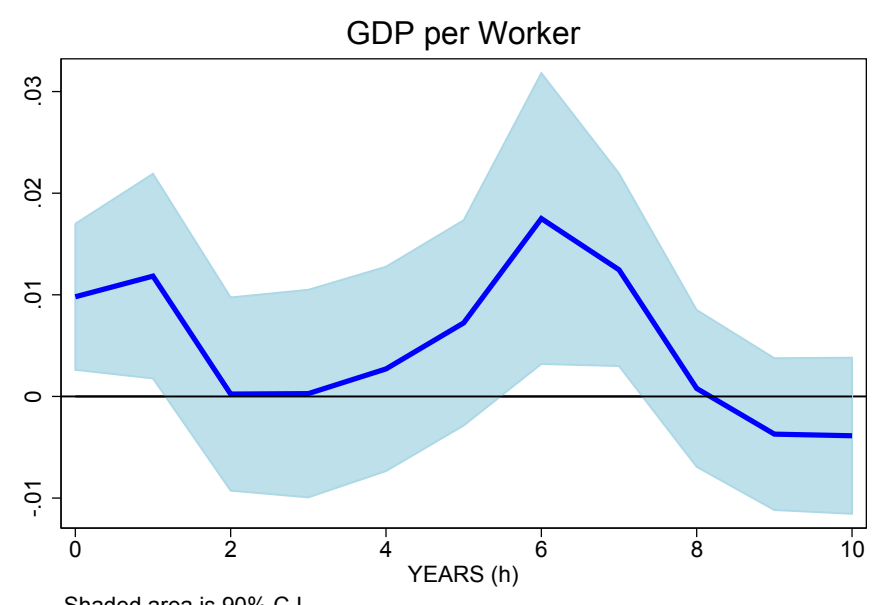

Shaded area is $90 \%$ C.I.

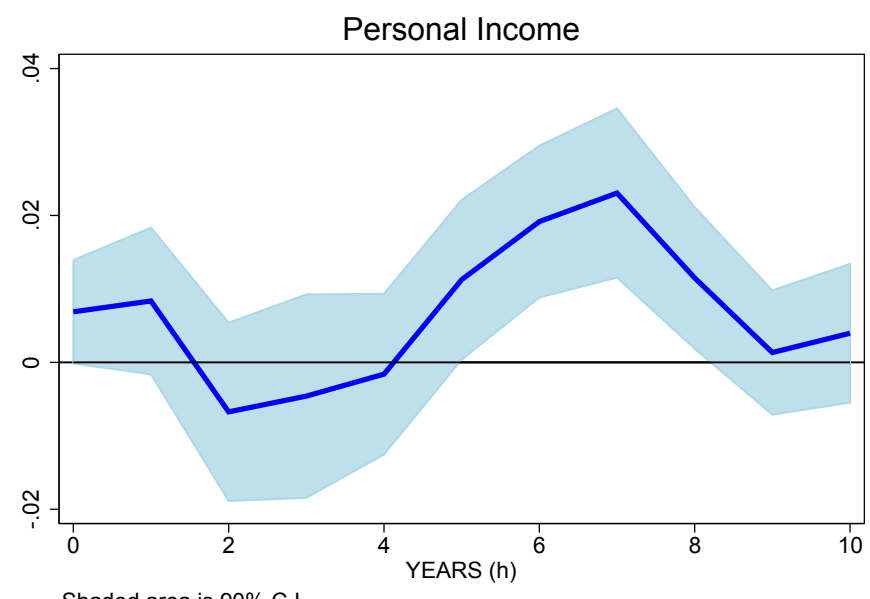

Shaded area is $90 \%$ C.I

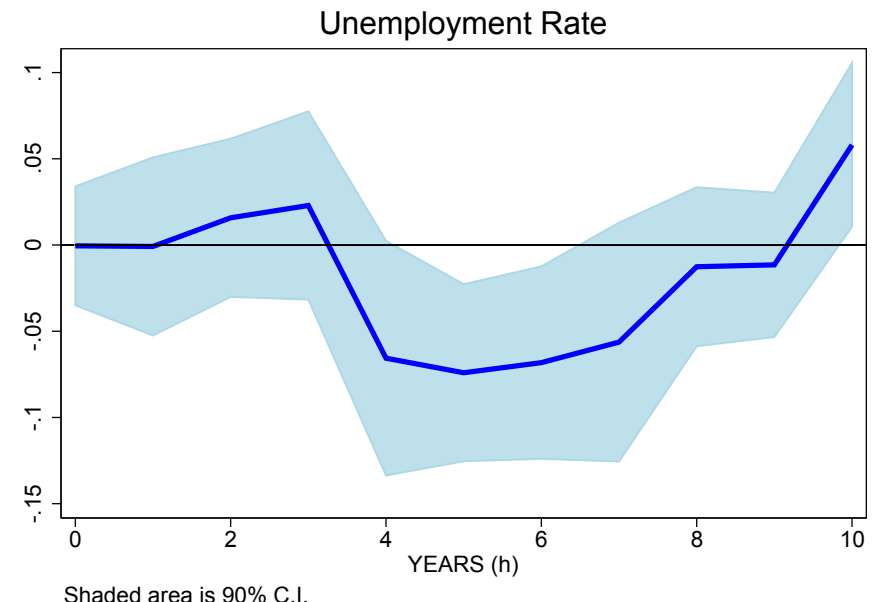

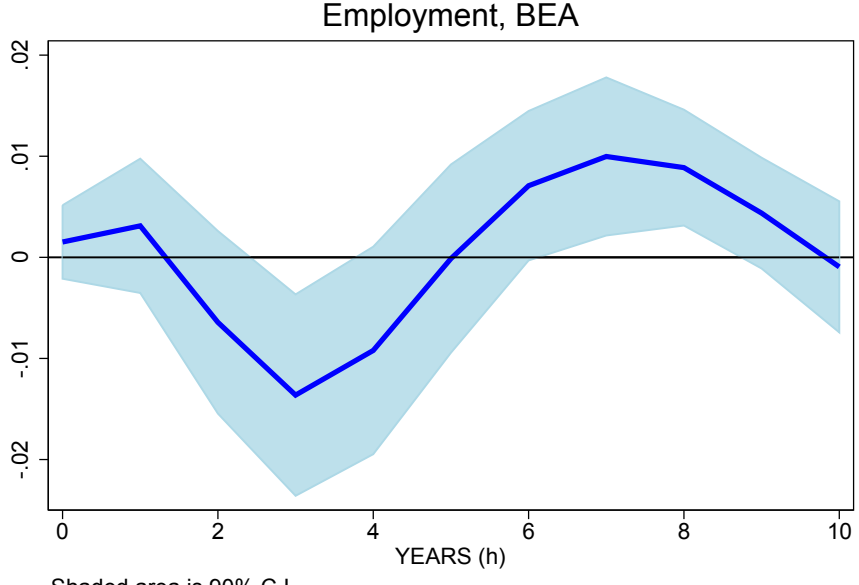

Shaded area is $90 \%$ C.I.

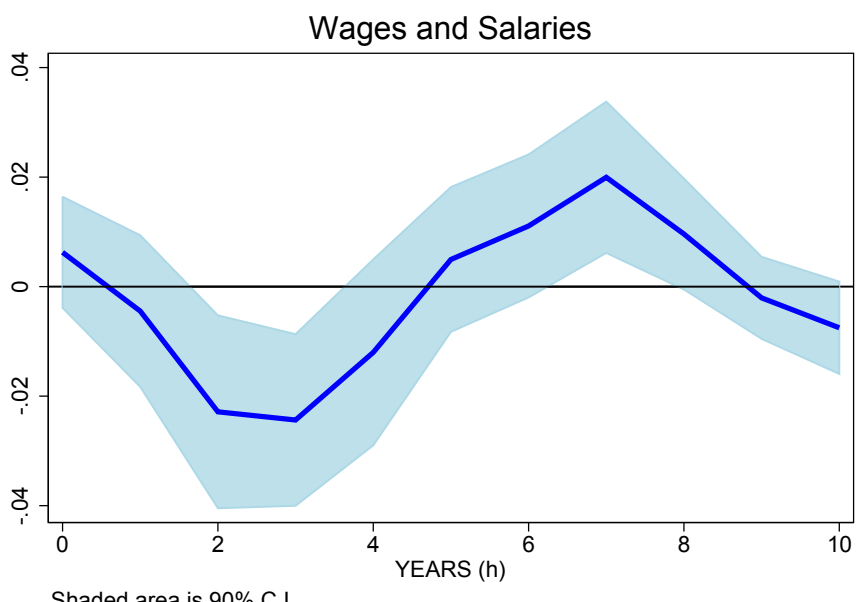

Population

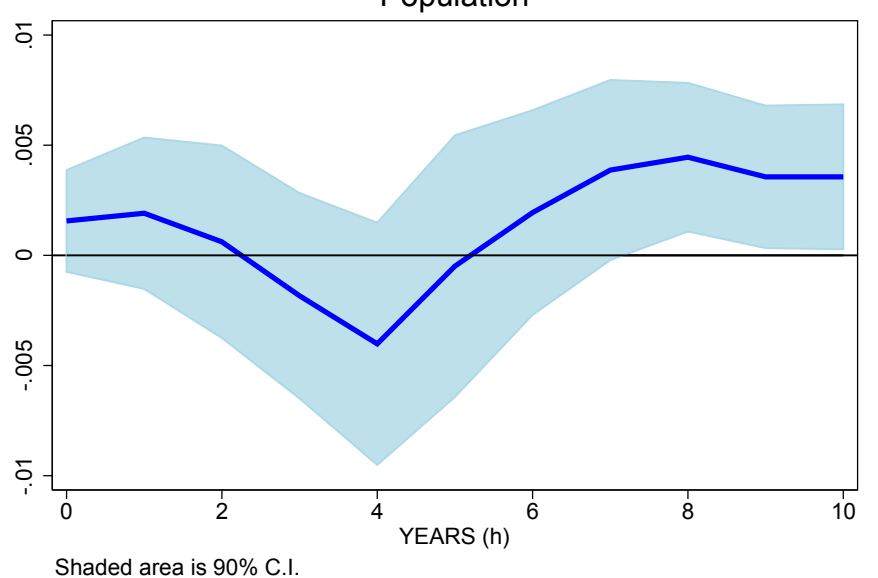




\section{Figure 7}

FHWA Grants

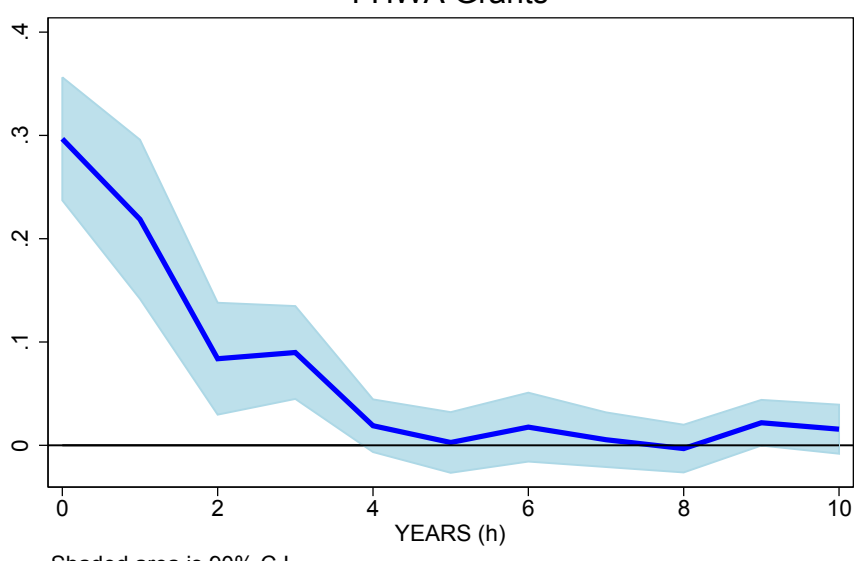

Shaded area is $90 \%$ C.I.

FHWA Outlays

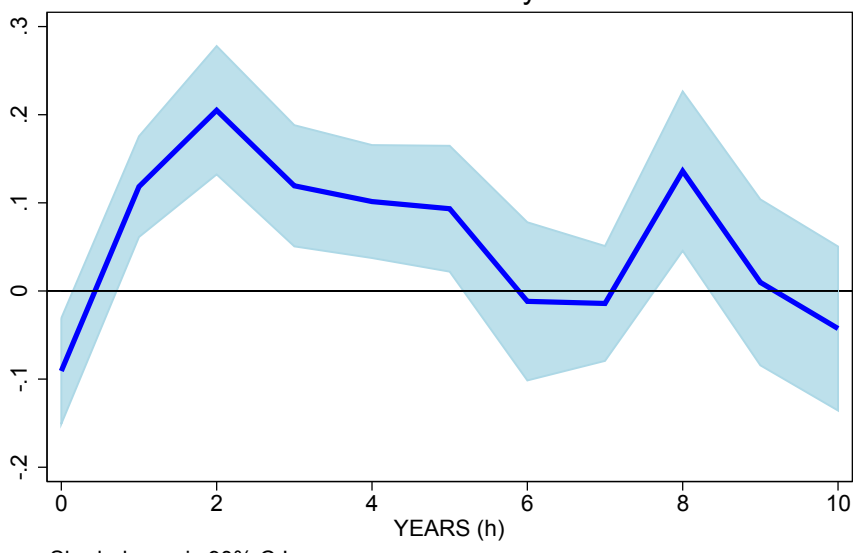

Shaded area is $90 \%$ C.I

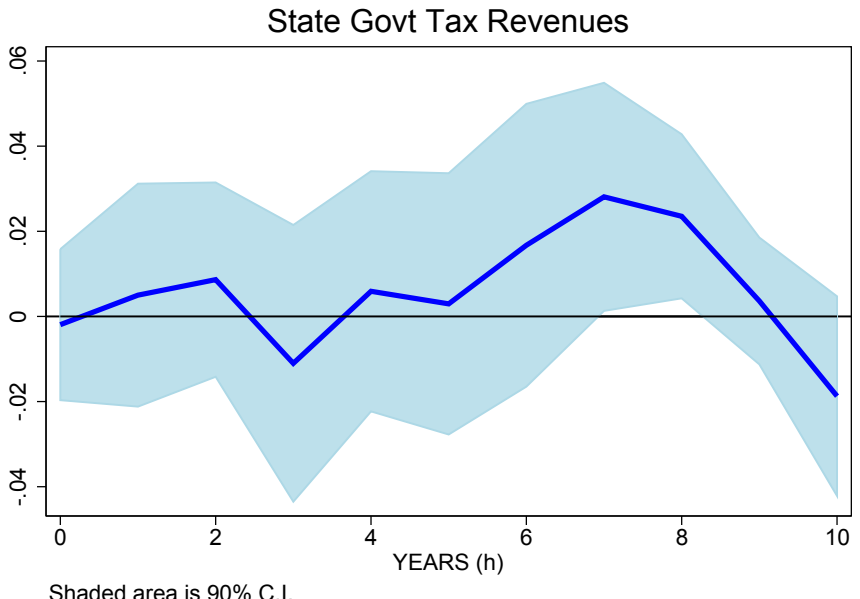

Shaded area is $90 \% \mathrm{C} . \mathrm{I}$

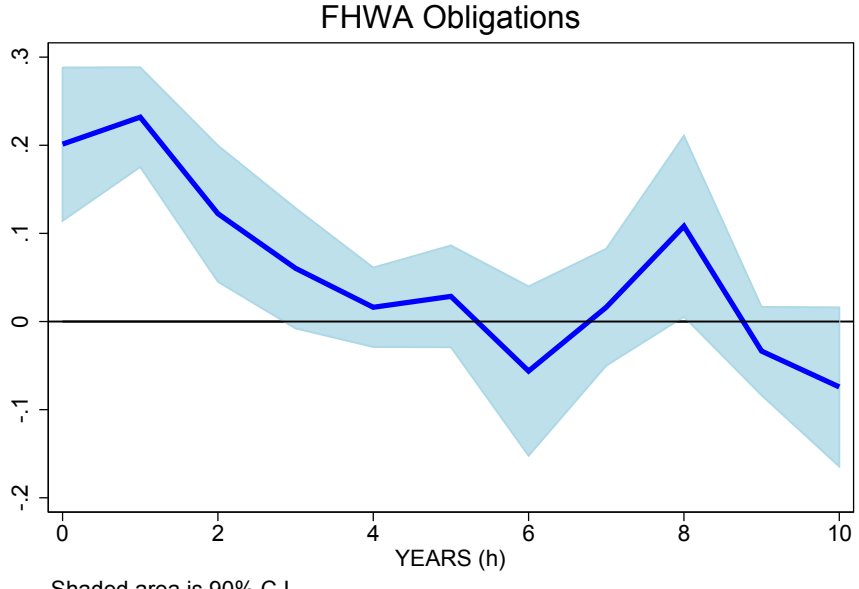

Shaded area is $90 \%$ C.I.

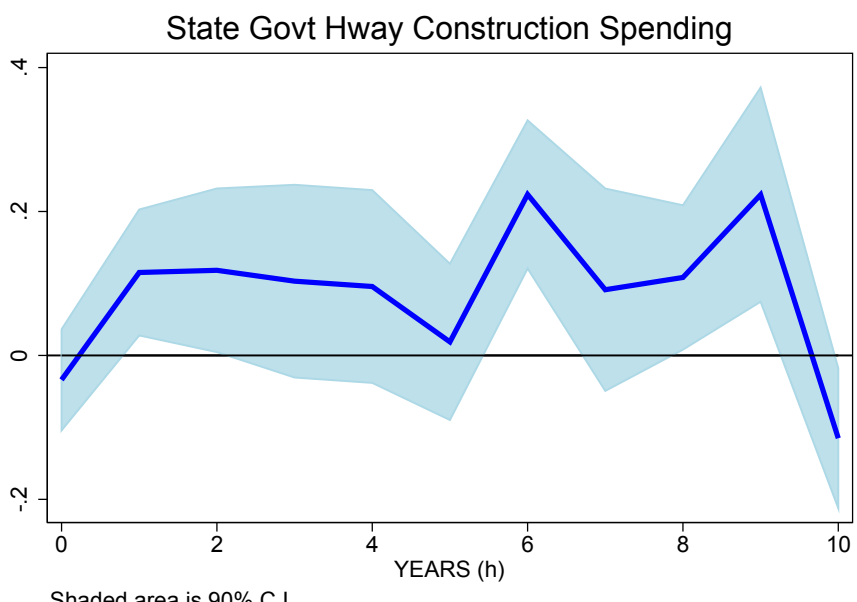

Shaded area is $90 \%$ C.I.

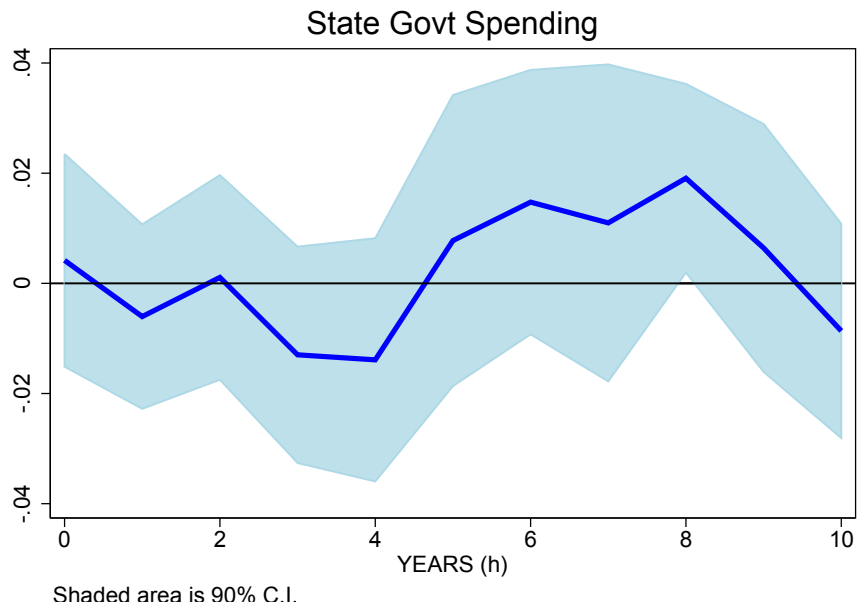

Shaded area is $90 \%$ C.I. 


\section{Figure 8}
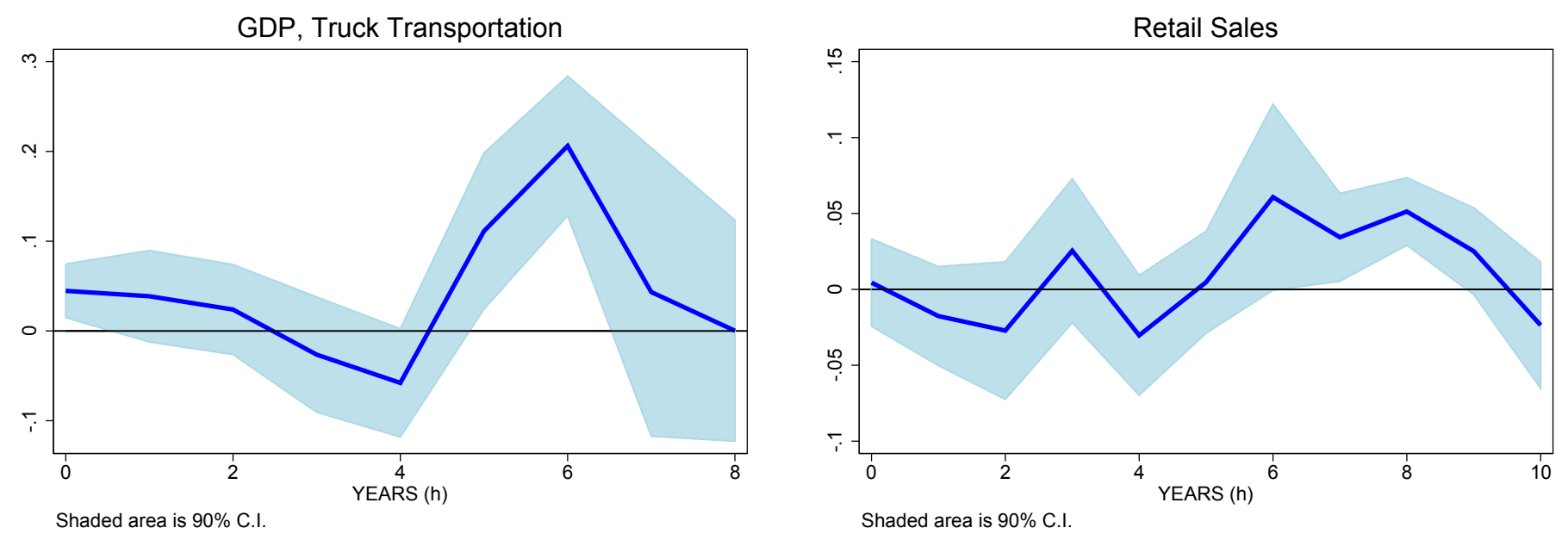


\section{Figure 9}

Panel A

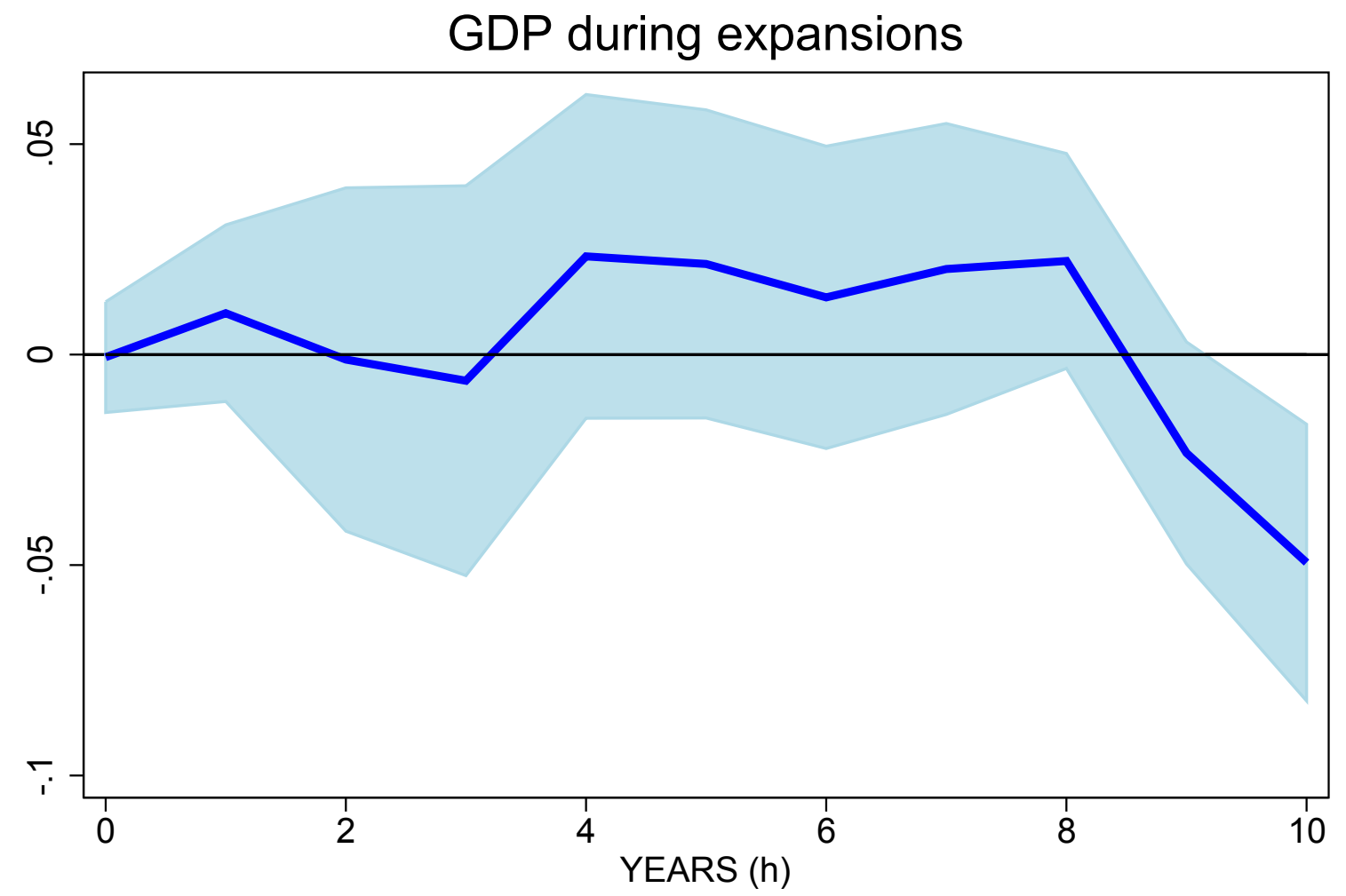

Shaded area is $90 \%$ C.I.

Panel B

GDP during recessions

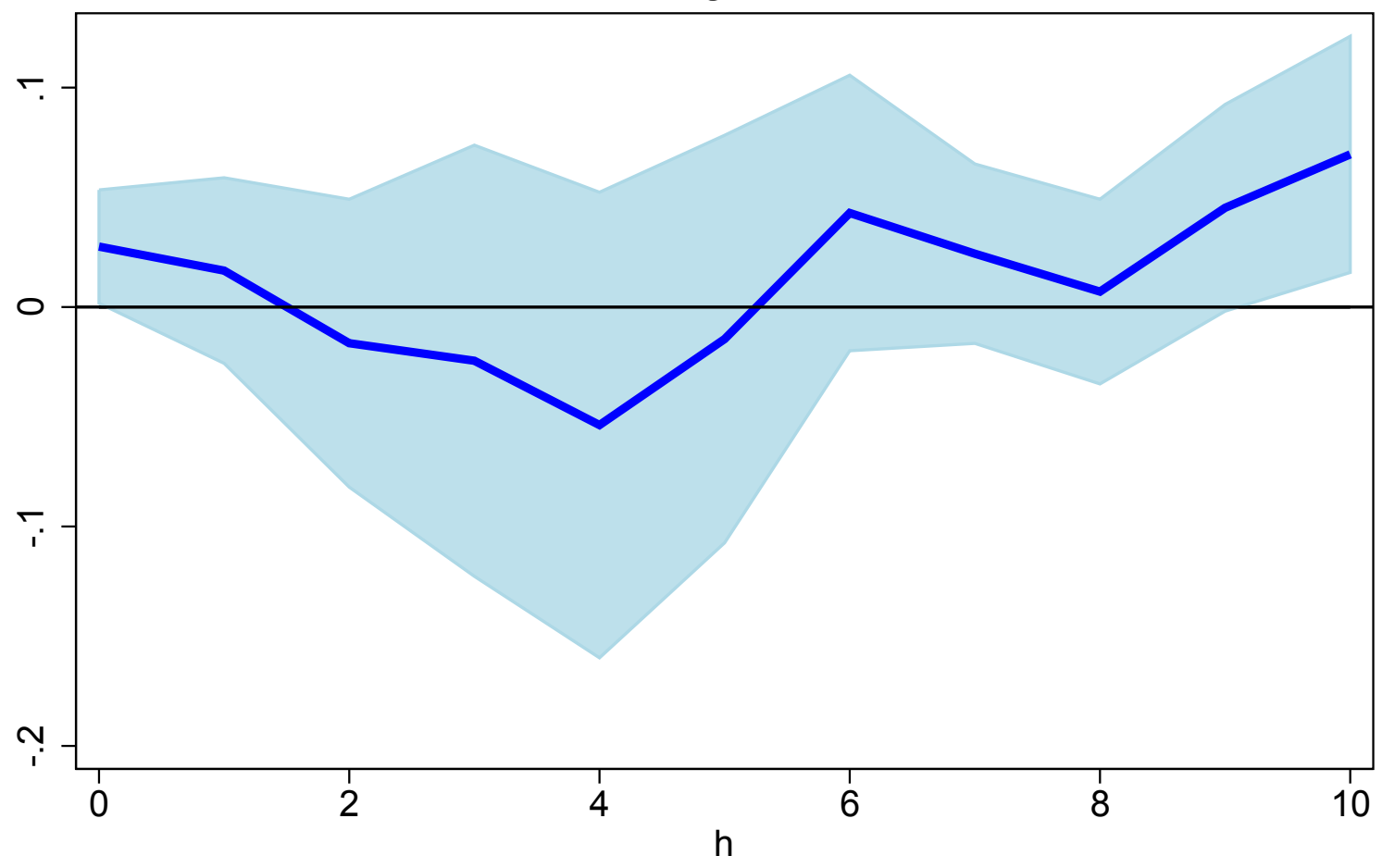

Shaded area is $90 \%$ C.I. 
Figure 10

Responses to a Home Increase in Public Spending

\section{Baseline Local Multiplier}

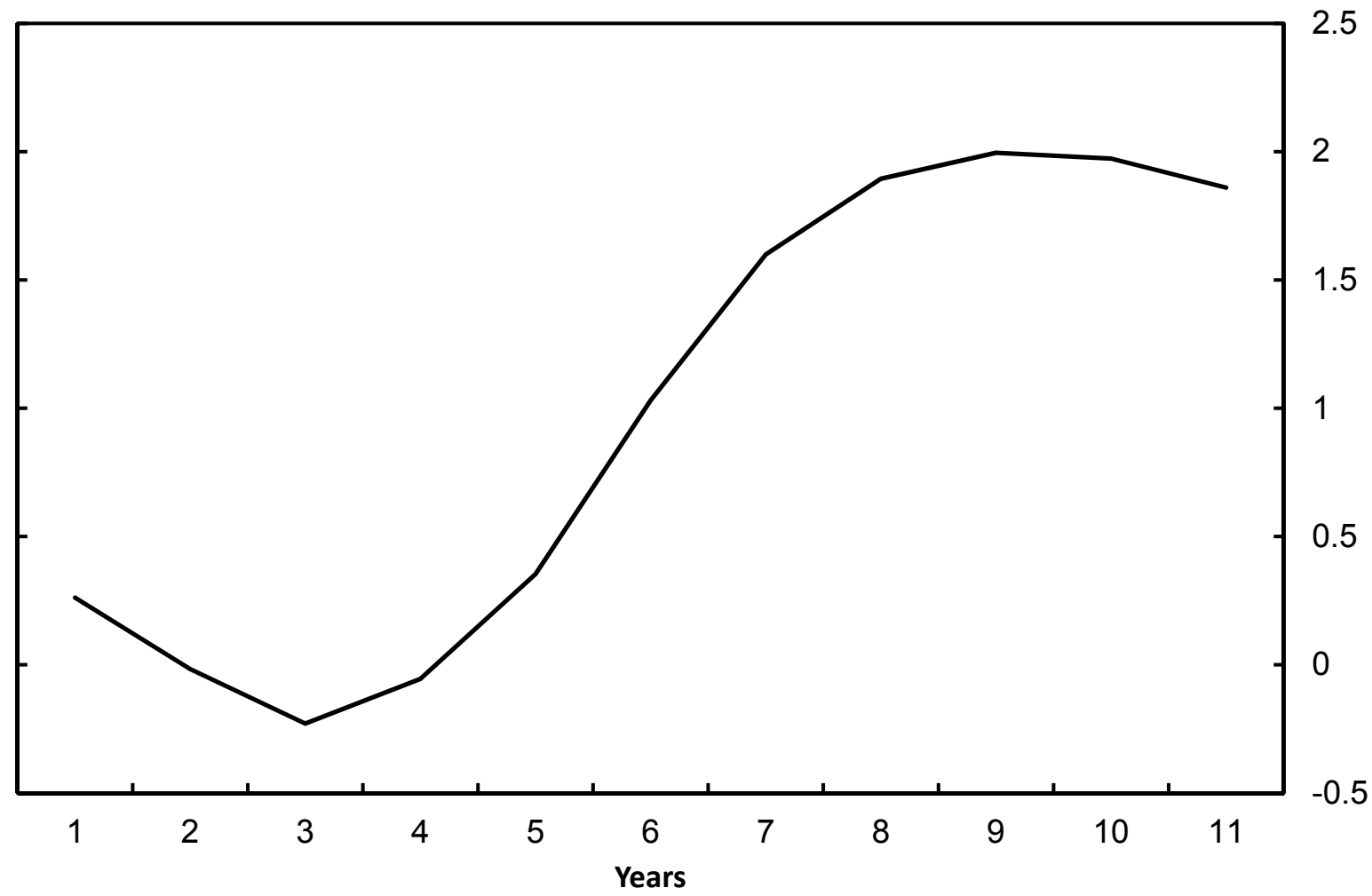


Figure 11

Theoretical Multipliers
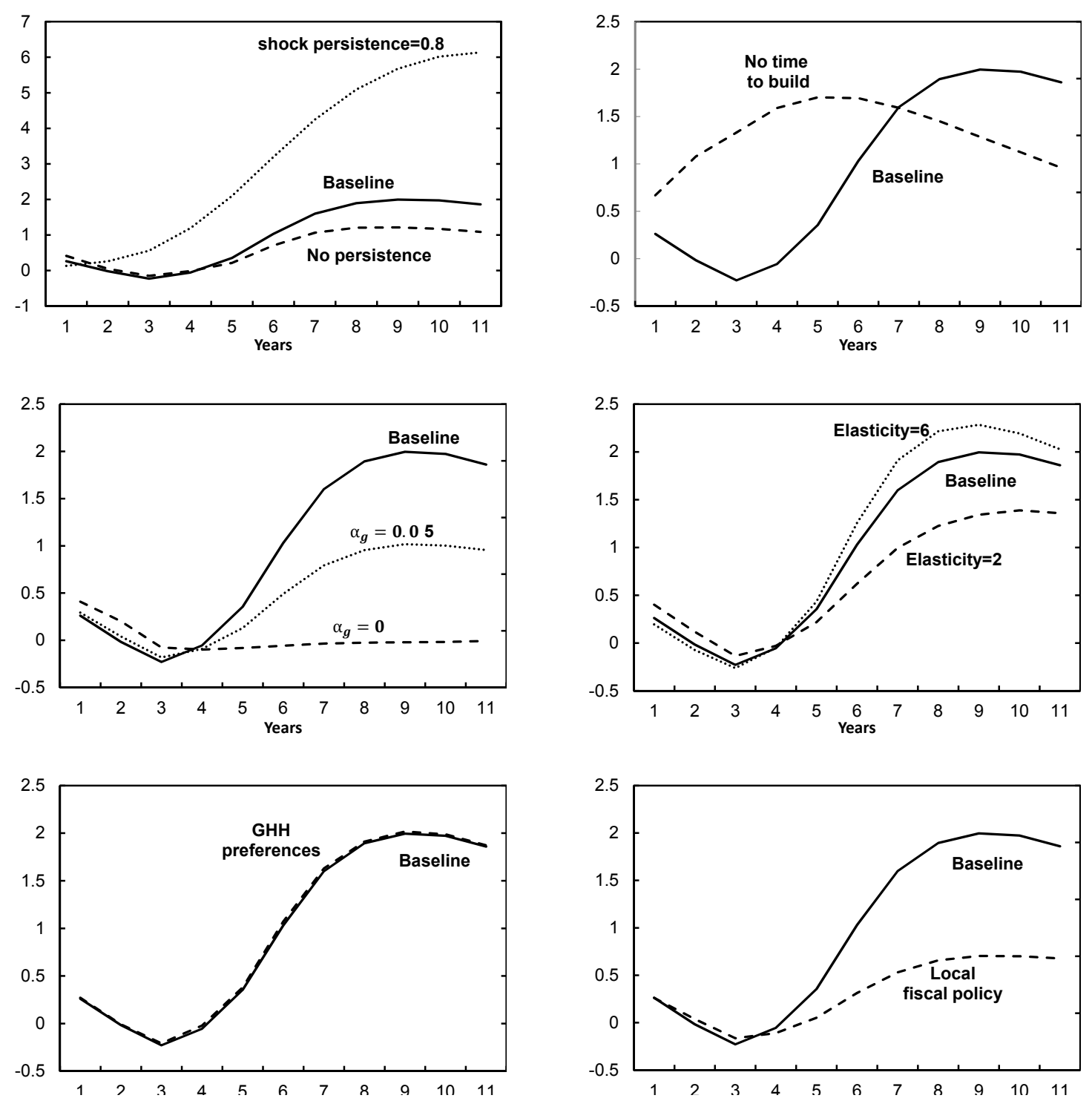
Appendix Figure 1

Robustness Checks

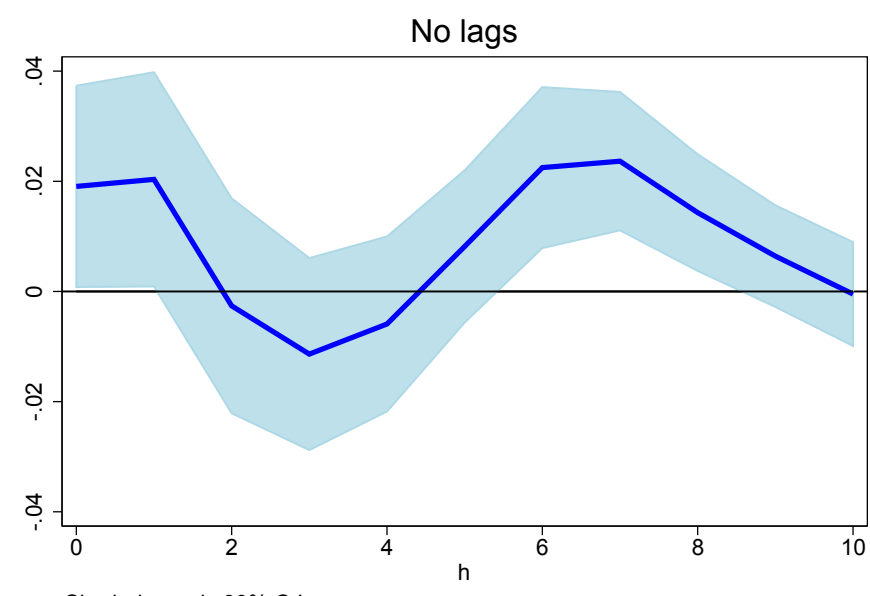

Shaded area is $90 \%$ C.I.

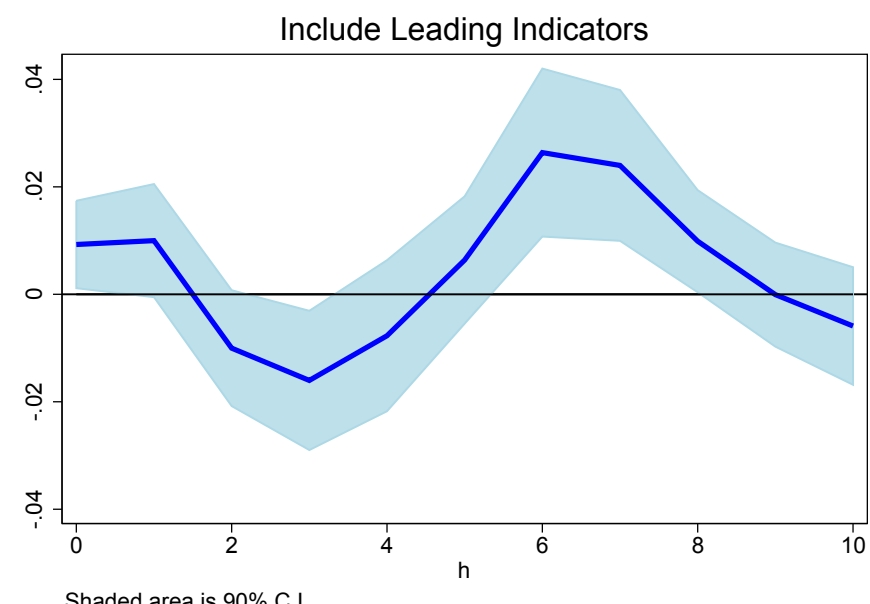

Shaded area is $90 \%$ C.I.

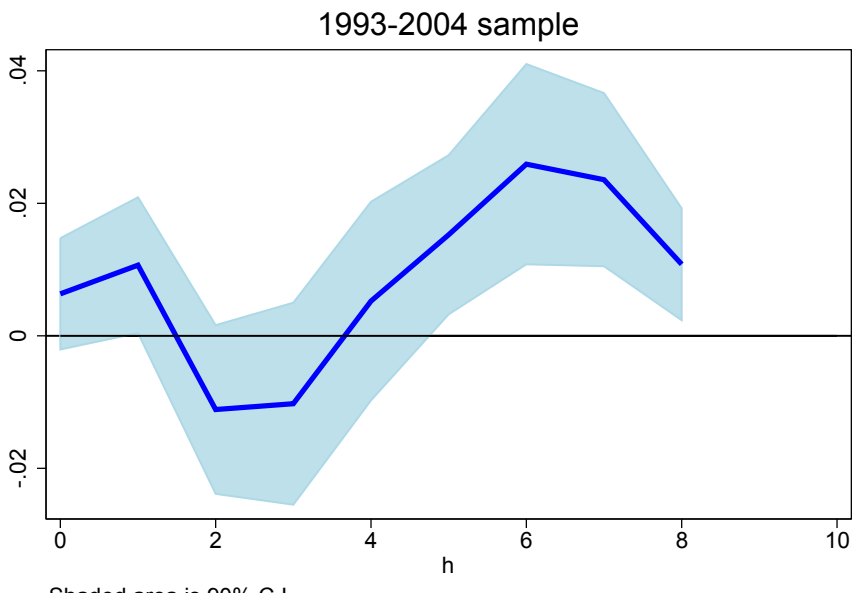

Shaded area is $90 \% \mathrm{C} . \mathrm{I}$

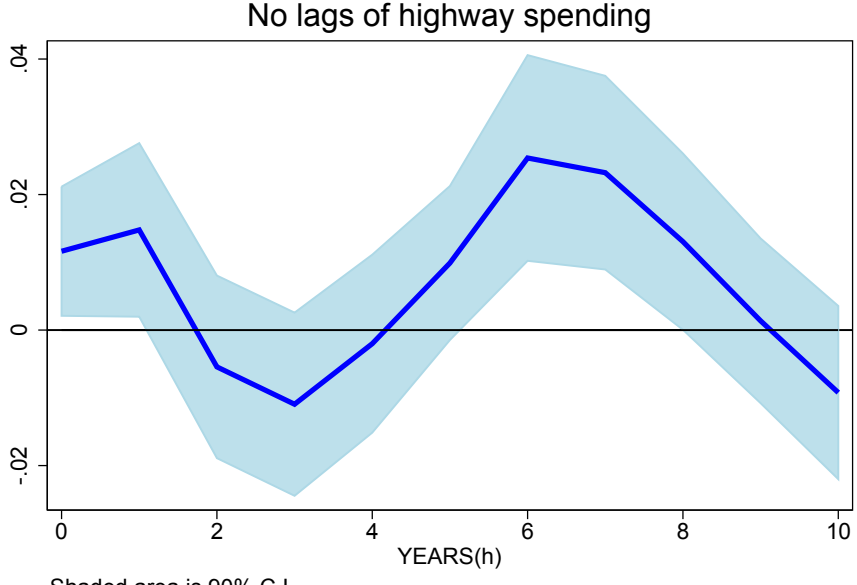

Shaded area is $90 \%$ C.I.

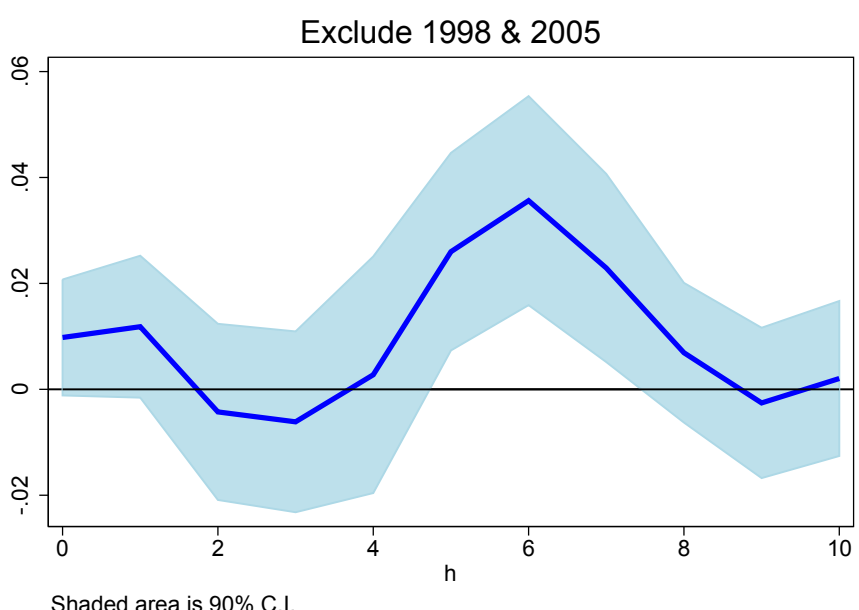

1999-2010 sample

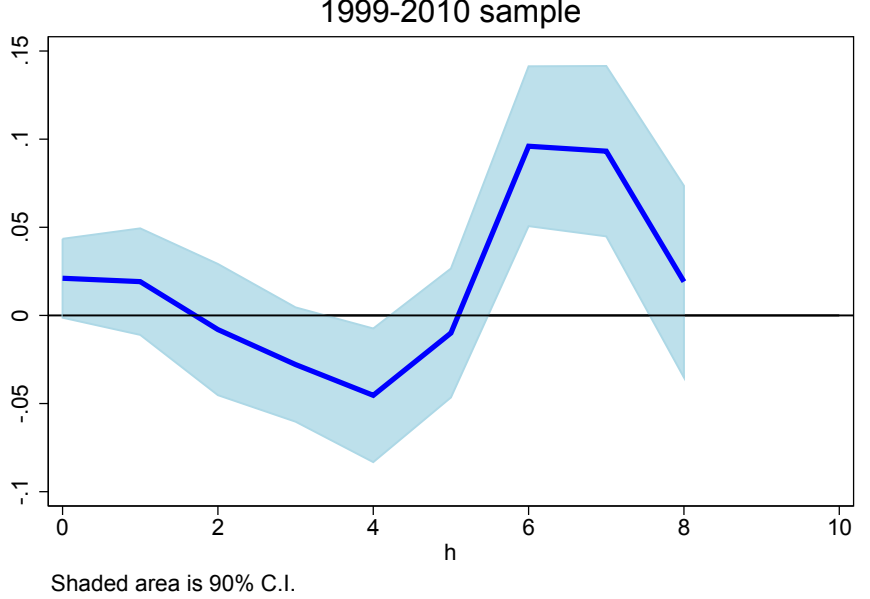

